\title{
Nanostructured Organic and Hybrid Solar Cells
}

\author{
Jonas Weickert, Ricky B. Dunbar, Holger C. Hesse, Wolfgang Wiedemann, \\ and Lukas Schmidt-Mende*
}

This Progress Report highlights recent developments in nanostructured organic and hybrid solar cells. The authors discuss novel approaches to control the film morphology in fully organic solar cells and the design of nanostructured hybrid solar cells. The motivation and recent results concerning fabrication and effects on device physics are emphasized. The aim of this review is not to give a summary of all recent results in organic and hybrid solar cells, but rather to focus on the fabrication, device physics, and light trapping properties of nanostructured organic and hybrid devices.

\section{Introduction}

The supply of clean energy for our society is a central challenge to maintain our standard of living. It is important to change from fossil fuels to renewable energy sources for two main reasons: Firstly, the natural resources of gas and oil are limited and will run out. Secondly and more importantly, a continued dependence on fossil fuels would increase an already alarming rate of $\mathrm{CO}_{2}$ emission. Additionally, other environmental problems such as oil spills, etc. caused by the mining of these resources may increase because the remaining resources will be in places which are more difficult to reach, e.g. far below sea level. Solar cells are promising candidates for $\mathrm{CO}_{2}$ emission free energy supply. However, the technology is still too expensive for their standing in competition against other energy sources. Novel types of solar cells featuring abundant organic semiconductors have the potential to emerge as energy generation devices that can be cheaply produced in large quantities. ${ }^{[1]}$ Even though the efficiencies of organic and hybrid solar cells are still limited, it is expected that their efficiency will continue to increase. The highest reported efficiencies of organic solar cells are currently over $7 \%$ and it is expected that $10 \%$ will be reached in the next year or two. ${ }^{[2]}$ Compared to conventional solar cells these values are still low. However, it should be mentioned that the progress in this field over the last ten years has been tremendous with an increase in efficiency by a factor of $-3 \cdot{ }^{[3]}$

Hybrid solar cells (HSCs) incorporating both organic and inorganic semiconducting materials aim to combine the

J. Weickert, R. B. Dunbar, H. C. Hesse, W. Wiedemann, Prof. L. Schmidt-Mende

Department of Physics \& Center for NanoScience (CeNS)

Ludwig-Maximilians University (LMU) Munich

Amalienstr. 54, 80799 Munich, Germany

E-mail: L.Schmidt-Mende@physik.uni-muenchen.de advantages of both material classes. The most efficient hybrid solar cells are dyesensitized or Grätzel solar cells (DSSC). Here, a mesoporous $\mathrm{TiO}_{2}$ film is sensitized with a monolayer of dye molecules, filled with an iodide/triiodide-based electrolyte and capped with a platinum counter electrode. Fast electron transfer from the photoexcited dye into the conduction band (CB) of the $\mathrm{TiO}_{2}$ takes place. The oxidized dye molecules are regenerated by the iodide redox couple, the positive charge being transported through the electrolyte to the platinum counter electrode. ${ }^{[4]}$ This type of solar cell has achieved efficiencies as high as $11 \%{ }^{[5]}$ There are several approaches to replace the liquid electrolyte with a solid organic hole-transporting material. Holes are directly transferred from the dye to this material and transported to the counter electrode. These solid-state dye sensitized solar cells (SS-DSSC) have not yet reached the same efficiencies as their liquid electrolyte counterparts.

In organic solar cells, the morphology of the semiconducting thin film is critical for the device performance. ${ }^{[6,7]}$ This has been the motivation for developing nanostructured organic or metaloxide materials for solar cell architectures.

This review will focus on nanostructured organic and hybrid solar cells. We will exclude deliberately liquid electrolyte dyesensitized solar cells, although control over the nanostructure of mesoporous films may have some advantages. The interested reader is instead referred to other review articles describing progress in liquid electrolyte dye-sensitized solar cells. ${ }^{[5,8-14]}$ Here, our focus will be on recent developments of organic and hybrid solar cells that have been brought about through control of the device nanostructure.

It is expected that nano-architectured solar cells will have some advantages over standard bulk-heterojunction solar cells. The fundamental operating principal in an organic or hybrid solar cell is identical. Light is absorbed by at least one of the photoactive materials and creates electron-hole pairs, so called excitons. These excitons have a binding energy of around $0.5 \mathrm{eV}$, which must be overcome for exciton separation. Exciton separation can be energetically favorable if the exciton can diffuse to a heterojunction of two device materials which have an offset between the respective highest occupied molecular orbital (HOMO) and lowest unoccupied molecular orbital (LUMO) levels. Following separation, the free charge carriers can then be extracted by the electrodes. A major loss mechanism inside the cell is charge carrier recombination. The device morphology can influence the exciton separation and charge collection kinetics to a large extent. Therefore, an important 
question is: What is the ideal morphology? Even after decades of research into hybrid and organic devices this is still largely an open question. However, some design rules can be listed ${ }^{[15]}$ : The domain size of donor and acceptor material should be small compared to the exciton diffusion length. For many polymers the exciton diffusion length is $10 \mathrm{~nm}$ or even smaller. In addition to the morphology, the electrochemical potential drop at the donor-acceptor interface must be sufficiently large to overcome the exciton binding energy. The formed geminate pair must be split into free charges before recombination occurs. The free charge carriers can be transported to the electrodes. This process is governed by the charge carrier mobility of the materials, which also influences strongly the device performance. Therefore, both electron and hole mobility should be high enough to extract charges efficiently. A balance between hole and electron mobility will prevent build up of space charge, which leads to declined charge extraction. High charge carrier mobility will allow fast charge extraction and decrease the probability of charge recombination while the charges travel to the electrodes. However, if the mobility is too high it will allow diffusive dark currents which will lower the open circuit voltage of the cell. ${ }^{[16]}$ In standard bulk-heterojunction solar cells processed from solution the device morphology cannot be precisely controlled. By selection of solvent, spin-coating conditions, etc., it is only possible to influence the phase separation of the organic films.

The same is also true in evaporated small molecule solar cells. The research on nanostructured solar cells with full control over the structure, especially the interfacial area of donor and acceptor materials, addresses the challenge of fabricating the "ideal" nano-morphology. In these devices, large interfacial areas and direct percolation pathways to the electrodes are realized. In metal-oxide nanostructures the charge carrier mobility can be influenced by increasing the crystallinity of the material or doping with additional elements. Even though nanostructured hybrid solar cells possess these advantages, current nanostructured devices show performances far below the standard bulk-heterojunction cells. We see the main reason in this lower performance not in the concept, but rather in the realization of the cells which is still far from optimal. The control of the structure down to dimensions of $\sim 10 \mathrm{~nm}$, comparable of the exciton diffusion length in polymers, is still a challenging task. Most nanostructured solar cells show dimensions larger than $50 \mathrm{~nm}$. Only if these dimensions become significantly smaller the performance of nanostructured devices will improve over that of standard bulk heterojunction solar cells. Nanostructured devices with defined morphologies and interfaces will also allow a better understanding of the physical processes in the devices.

There are still many physical mechanisms in organic and hybrid solar cells that need to be better understood. Defined nanostructures will enable us to investigate questions such as, among others, whether a) exciton separation happens preferably in direction of the external field given by the difference in work-functions of the metal electrodes or also in opposed direction, b) the interface can be designed to efficiently enable charge injection but hinder charge recombination, c) there is a maximum size of the nanostructure needed to allow efficient charge transport d) additional effects based on the nanodimensions start to play a role when the dimensions get smaller than
$10 \mathrm{~nm}$ and e) plasmonics and other light trapping approaches can significantly enhance the device efficiency.

In the next sections we will report on different strategies to achieve the desired nanostructures. Here it will be necessary to differentiate between fully organic and hybrid solar cells. Nanostructuring of organic solar cells can be achieved by self-assembly or nanoimprint lithography. Metal oxides nanostructures are usually prepared by facilitation of self-organized growth mechanisms. We will report on nanowire, nanotube and nanonetwork structures and the different synthetic routes for these structures. Even so there is a huge variety of available metal-oxides, our report will focus on the most common materials, such as $\mathrm{TiO}_{2}$ and $\mathrm{ZnO}$. In the last section of this article we address the interaction of light with device nanostructures, especially metallic. The interaction can lead to enhanced light scattering and plasmonic field enhancement, improving the device performance.

\section{Fully Organic Solar Cells (OPVs)}

One of the main challenges in the field of organic photovoltaics (OPVs) is achieving complete exciton harvesting while maintaining minimal losses due to recombination. As mentioned above, the exciton diffusion length in organic semiconductors is typically short, often below $10 \mathrm{~nm}$. A donor acceptor intermixing with a nanometer length scale phase separation is therefore conducive to efficient harvesting of excited states. ${ }^{[17,18]}$ However, direct percolation pathways to the respective electrodes are necessary to suppress charge carrier trapping and recombination. High charge carrier mobility and lifetime in the respective phases also lead to high performance as can be seen in Figure $1{ }^{[19]}$ Therefore, architectures of highly crystalline and ordered materials with intimate contact of donor and acceptor phase on the nanometer length scale are desired for improved efficiency. ${ }^{[20,21]}$ The synthesis of highly pi-conjugated molecules

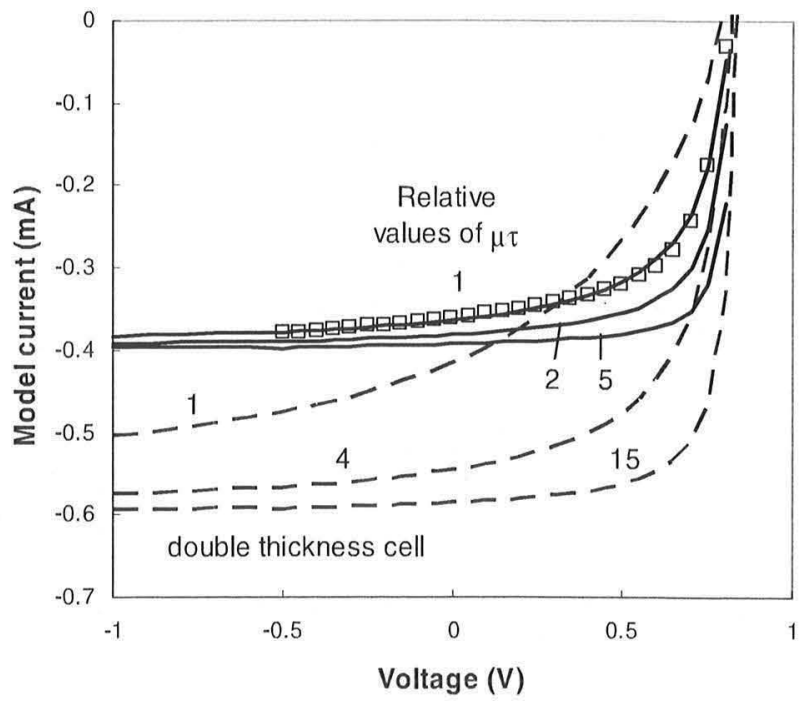

Figure 1. Snapshot from Ref. 19 showing the potential of increased mobil ity-lifetime product. Reprinted with friendly permission of R. A. Street. 
with functional groups fostering self-assembly into mesoscopic and macroscopic architectures is a versatile tool to achieve this goal.

In the following paragraphs we will introduce a number of different approaches aiming to control the nano-morphology of organic/organic heterojunction solar cells.

\subsection{Small Molecules}

The facile synthesis of small molecules, where high purity and monodispersity is possible, is an advantage compared to that of the materials used in polymer-based solar cells. High cristallinity and mobility can thus be achieved. ${ }^{[22]} \mathrm{A}$ bi-layer stack of small molecules also served as the photoactive layer in the first organic solar cell with an efficiency of over $1 \%$ by Tang et al. in $1986 .{ }^{[23]}$ However, when the bulk heterojunction approach is used for small molecules, strong recombination often drastically limits the performance. ${ }^{[24]}$ It has been shown that due to their compatible size and often comparable stacking properties, fully intermixed blends of donor and acceptor molecules are formed. ${ }^{[25]}$ This can result in a pronounced photoluminescence quenching despite a significant loss of free charge carriers due to bimolecular recombination and incomplete charge carrier pathways to the electrodes. A de-mixing of the donor and acceptor molecules induced by the introduction of hydrophilic and hydrophobic substituents, respectively, or using molecules with incompatible size is believed to reduce this unfavorable molecular stacking. ${ }^{[26]}$ Controlling morphology and molecular alignment in small molecule donor-acceptor systems is a key issue and might help to access the outstanding properties of the pristine materials.

In order to span the molecular organization from microscopic to mesoscopic or even macroscopic length scales, liquid crystalline (LC) materials have been shown to hold great promise. ${ }^{[27,28]}$ The supra-molecular interactions in LCs allow a better organization on the molecular scale when compared to the isotropic phase ${ }^{28]}$ Furthermore, due to the avoidance of grain boundaries commonly found in crystalline phases an unhampered charge carrier transport can be provided also in the bulk material. Therefore, these materials very well meet the requirements as active layers in OPV devices.

A variety of different molecules has been found with LC properties, often showing multiple phase transitions and having phases with different levels of supra-molecular organization. When heated to an isotropic state, external stimuli such as electric ${ }^{[29]}$ or magnetic ${ }^{[30]}$ fields can induce long range orientation of the molecules which may be retained in the LC state. Furthermore, local defects in the supra-molecular organization can be overcome by a self-healing procedure which is highly desirable for increased device lifetimes. ${ }^{[31]}$

Liquid crystal materials can form 1D organic nanowires, which display high charge carrier mobility along the nanowire axis. ${ }^{[32]}$ Combined with strongly absorbing acceptor molecules, a remarkable solar cell efficiency of $1.95 \%$ has been reported at low light intensities. ${ }^{[33]}$

If the molecules are stacked with a face-on alignment to the substrate plane (homeotropic alignment), charge carriers can be extracted more efficiently, even at higher generation rates. The use of a sacrificial capping layer ${ }^{[34]}$ or specially functionalized molecules ${ }^{[35]}$ allow for this favorable alignment on transparent electrode materials.

However, the full potential of LC materials is yet to be realized in solar cell applications. It remains a great challenge to simultaneously orient and organize the donor and acceptor molecules. A recent study has shown the successful orientation of two LC molecules in a bi-layer geometry. ${ }^{[36]}$ This might be a step towards the fabrication of solar cells based on highly oriented LC materials.

In order to access more sophisticated interface architectures, pre-orientation of either donor or acceptor material is a natural approach. Both hybrid solar cells - discussed later - and polymerization assisted methods seem appealing.

An entirely different approach feasible for a large number of small molecules is vacuum sublimation and co-evaporation of organic materials. The best devices are based on the p-i-n model and the reader is referred to a comprehensive review by K. Walzer. ${ }^{[3]}$

\subsection{Di-Block Co-Polymer Approach}

The use of di-block copolymers is another promising approach to achieving controlled active layer morphologies. Here, repeat units of donor and acceptor are covalently bound to each other. Upon solvent evaporation self assembly of the building blocks drives the formation of highly ordered architectures. The size and type of linker unit between donor and acceptor oligomers and their respective weight fraction determines the phase formation and thus the resulting nano-architecture. This direct morphology control is a clear advantage compared to the polymer-fullerene systems, which exhibit the best power conversion efficiencies to date. Ordered nanostructures with different shapes have been realized by this method (Figure 2). ${ }^{[26]}$ This self-assembly has been mainly studied on non-conducting polymers and only more recently also semiconducting di-block co-polymers have been synthesized. Since the first successful application of this concept by S. Sun ${ }^{[38]}$ a variety of different donor and acceptor moieties has been tested with high intrinsic absorption and mobility. However, up to date the efficiency of these devices remains still far below $1 \%$, which is mainly attributed to high series resistance and significant recombination losses. ${ }^{[39]}$ Despite a high exciton separation yield indicated by significant photoluminescence quenching, strong recombination at covalent bonding sites of the polymer backbone limits the overall performance.

Optimization of the alignment yielding the formation of wire-like structures perpendicular to the substrate plane and the insulating spacer units may help to improve the efficiency of these devices. It should also be noted that the synthesis of these macromolecules with minimized polydispersity and high yield remains a challenging task.

\subsection{Nanoimprint Lithography}

Mechanical lithography, often called hot embossing or nanoimprint lithography (NIL), was first discovered by Chou et al. It is a useful technique in the field of nanoscience ${ }^{[40,41]}$ and 
Hole-conducting Block Electron-conducting Block

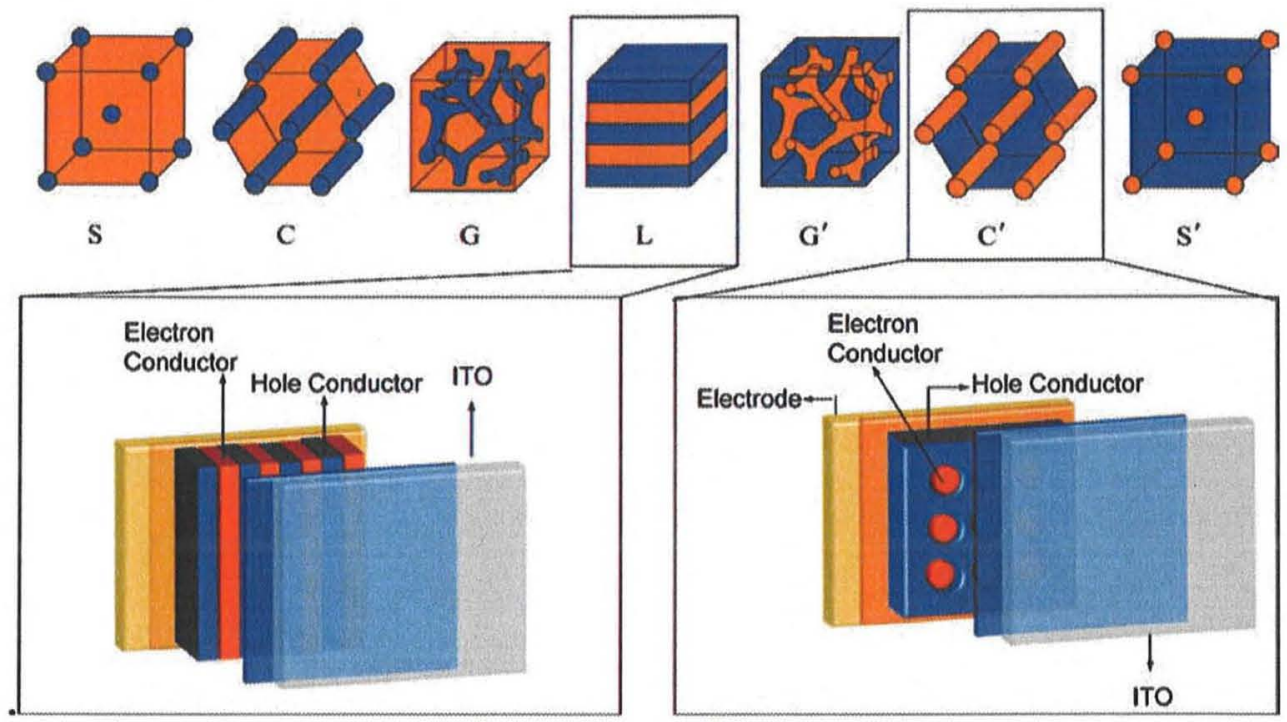

Figure 2. Schematic showing different morphologies which can be realized by choosing appropriate di-block co-polymers. Reprinted with permission. ${ }^{[26]}$ Copyright 2010 American Chemical Society.

provides another method of controlling the nanostructure of the active layer in organic solar cells. Figure 3 illustrates the simple working principle of the procedure. A mold is pressed into an organic film. After removal of the mold the film has the structure defined by the mold. The process allows finetuning through parameters such as pressure, duration and temperature. An alternative method exposes the mold and substrate to solvent vapor atmosphere and is called solvent assisted nanoimprint lithography (SANIL). It is an easy and versatile method that can achieve high aspect ratio imprints without the need of high pressures or temperatures. This treatment effectively lowers the glass-transition temperature and decreases the viscosity of the polymer by many orders of magnitude. This is important because the narrow window between glass transition and thermal degradation temperature limits the range of viscosities at which NIL can operate. One tremendous advantage of NIL compared to traditional lithographic methods is that its resolution is not limited by factors such as wave diffraction, scattering and interference. As a result, it is possible to use NIL to replicate patterns with sub- $10 \mathrm{~nm}$ accuracy. ${ }^{[42]}$ Nanoimprint
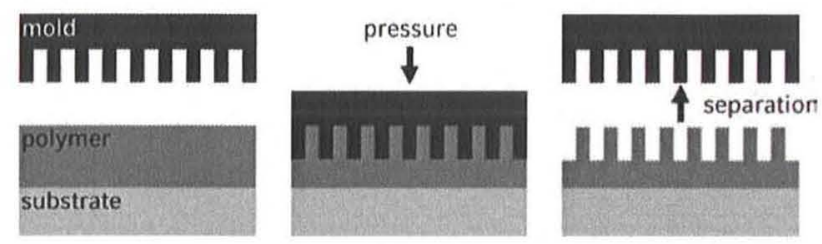

Figure 3. Schematic of the working principle of nanoimprint lithography. A thin organic film is fabricated on a substrated and imprinted with a mold. After separation, the pattern of the mold is transferred to the organic layer. lithography and related technologies were originally designed for applications with the need of sub-micrometer features in the lateral dimension such as transistors, high-density data storage or organic light emitting diodes. When used in organic photovoltaic cells however, high-aspect ratio structures, i.e., very thin but high features, are desired to produce large surface area interfaces to facilitate efficient exciton dissociation. Fully organic/organic devices with nanostructured and defined interfaces have only been investigated by very few groups. The results of some important investigations are shown in Table 1.

Aryal et al. pioneered the fabrication and characterization of poly(3-hexylthiophene) (P3HT)/[6,6]-phenyl- $\mathrm{C}_{61}$-butyric acid methyl ester (PCBM) nanostructured heterojunctions. ${ }^{[43]}$ Using an Anodic Aluminum Oxide (AAO) membrane fabricated by a two step anodization process as an imprint stamp, a transfer method of the porous structure from the AAO to a silicon wafer by using reactive ion etching was developed. The strongly anisotropic nanohole array was then used to imprint P3HT, PCBM, photoresist SU-8, hydrogen silsesquixane and polymethylmethacrylate. The imprint was performed after applying an anti-sticking layer onto the mold and the temperature was chosen to be $20-50^{\circ} \mathrm{C}$ above the glass transition temperature of the chosen material. Using an orthogonal solvent combination, a layer of PCBM was spin-coated on top of the nanostructured ITO/poly(3,4-ethylenedioxythiophene):poly(4-styrenesulfonate (PEDOT:PSS)/P3HT architecture, followed by the evaporation of aluminum as the back electrode. Measuring current-voltage characteristics reveals the change in open circuit voltage $\left(\mathrm{V}_{\mathrm{OC}}\right)$, short circuit current $\left(\mathrm{I}_{\mathrm{SC}}\right)$, fill factor $(\mathrm{FF})$ and power conversion efficiency (PCE) due to the nanostructured interface. It has to be mentioned that this method of preparation of spin-coating a PCBM layer on top of the nanoimprinted P3HT layer creates 
Table 1. Nonexhaustive survey of reports on nanoimprint solar cells.

\begin{tabular}{|c|c|c|c|c|c|c|c|c|c|}
\hline Ref. & $\begin{array}{l}\text { Feature Height } \\
{[\mathrm{nm}]}\end{array}$ & $\begin{array}{l}\text { Feature distance } \\
\qquad[\mathrm{nm}]\end{array}$ & Aspect Ratio & $\begin{array}{l}\text { Feature Width } \\
\qquad[\mathrm{nm}]\end{array}$ & $\mathrm{T}\left[{ }^{\circ} \mathrm{C}\right]$ & $\begin{array}{c}\text { Pressure } \\
\text { [MPA] }\end{array}$ & Time [min] & Orientation & Technique \\
\hline [146] & 200 & 100 & 2,5 & 80 & 160 & $5 \mathrm{MPA}$ & 10 & Edge-On to vertical & Commercial Imprinter \\
\hline [191] & 300 & 300 & 1,2 & 250 & 250 & - & 30 & Edge-On to Vertical & Melt-assisted wetting \\
\hline [45] & 150 & 100 & 3 & 50 & 250 & - & 30 & Edge-On to Vertical & Melt-assisted wetting \\
\hline [192] & 80 & 50 & 3,2 & 25 & - & - & 20 & - & SANIL \\
\hline
\end{tabular}

a diffuse and slightly intermixed interface, rather than a strict bilayer. ${ }^{[44]}$ The slightly diffuse interface explains the high short circuit current observed in bilayer devices with flat and nanostructured interface. Nevertheless, an improvement in device performance for the nanostructured devices is observed due to an increase in interfacial area.

Similar results have been observed in structures where pores of an AAO membrane have been filled with P3HT using capillary action under vacuum. ${ }^{[45]}$ With dimensions as high as $150 \mathrm{~nm}$ in height, $100 \mathrm{~nm}$ pitch and $50 \mathrm{~nm}$ width, the cylindrical P3HT nanowires exhibit an aspect ratio of 3 and an additional interfacial area of 2.6 compared to a flat layer. X-ray data indicate a re-orientation of polymer chains from edge-on to face-on resulting in a conductivity increase by a factor of ten has been observed.

Nanostructured devices with evaporated $\mathrm{C}_{60}$ as electron acceptor show a strong photoluminescence quenching relative to the bilayer film indicating a good contact between the organic layers. The overall results indicate good filling of $\mathrm{C}_{60}$ within the P3HT matrix. The current-voltage curves show a short circuit current increase by a factor of 4 , with little change in $\mathrm{V}_{\mathrm{OC}}$ and a slight increase in $\mathrm{FF}$. The improved $\mathrm{FF}$ indicates smaller series resistance and can be attributed to more efficient charge transport and reduced recombination. Overall, a relative efficiency increase by a factor of 6 can be calculated, yielding an absolute PCE of $1.1 \%$. It should be noted that an intermixing at the polymer $/ \mathrm{C}_{60}$ interface during an applied post-process annealing can be assumed, as has been shown previously in poly[2-methyl, 5-(3,7 dimethyl-octyloxy)]-p-phenylene vinylene (MDMO-PPV)/ $\mathrm{C}_{60}$ bilayer devices. ${ }^{[46]}$ This is in very good agreement with our observations, when investigating and comparing annealed bilayer devices. We observed a short circuit current increase by a factor of four in a P3HT/PCBM bilayer device, which can be attributed to additional organic/organic interface induced by annealing. An increase of current due to an increase of crystallinity is very unlikely because it can be assumed that the crystallization in the as spun pristine materials is initially high. ${ }^{[47,48]}$ In order to investigate the effect of the nanostructured interface alone, we demonstrate a solar cell consisting of a well defined P3HT/PCBM layer, fabricated by a novel transfer technique. The $100 \mathrm{~nm}$ thick P3HT layer was imprinted with an AAO stamp exhibiting pores with about $50 \mathrm{~nm}$ diameter and an average pore-to-pore distance of $100 \mathrm{~nm}$. After imprinting, the surface was analyzed by scanning electron microscopy (SEM) and glancing incidence small angle X-Ray Scattering (GISAXS). By fitting the GISAXS data, the obtained structural parameters such as the average pillar height $(=35 \mathrm{~nm})$, pillar to pillar distance $(=80 \mathrm{~nm})$ and pillar radius $(=20 \mathrm{~nm})$ could be extracted. After transferring the PCBM film on top of the P3HT structures, additional GISAXS measurements were used to confirm the filling of the nanostructures. Solar cell results indicate a short circuit current increase of about $50 \%$, which correlates well with the increase of surface area. Both FF and $V_{\mathrm{OC}}$ increased slightly in the nanostructured cell..$^{[4]}$

A study based on P3HT and a small molecule acceptor was published by Zeng and co-workers. ${ }^{[50]}$ Very similar to the previous investigations, Zeng et al. produced a nanostructured array of P3HT by NIL with a silicon mold. The electron acceptor 4,7-bis(2-(1-ethylhexyl-4,5-dicyano-imidazol-2-yl)vinyl) benzol[c]1,2,5-thiadiazole (EV-BT) was used instead of PCBM. This allowed defined bilayers to be fabricated because of EV. BT's different solubility compared to P3HT. Devices with layered structures of ITO/PEDOT:PSS/P3HT/EV-BT/Ca/Ag with planar bilayers, nanostructured interfacial bilayers and blend morphologies were fabricated and characterized. Atomic force microscopy (AFM) images revealed a $100 \mathrm{~nm}$ pitch nano-hole array with about $50 \mathrm{~nm}$ wide and $25 \mathrm{~nm}$ deep holes. The short circuit current in the blend and nanostructured device increased compared to the bilayer by a factor of 3.7 and 2.3 respectively, indicating a good contact between the organic materials in the nanostructured device. The FF in the blend $(29 \%)$ and nanostructured cell (38\%) was limited, which could be due to imbalanced electron- and hole mobilites or an overall low electron mobility resulting in higher recombination. The pure bilayer solar cell exhibited the best FF of $55 \%$. All values are listed before annealing in order to discuss defined interfaces without any inter-diffusion.

An extensive study was performed by He et al. using P3HT as electron donor and poly((9,9-dioctylfluorene)-2,7-diyl-alt-[4,7bis(3-hexylthen-5-yl)-2,1,3-benzothiadiazole]-2',2"-diyl) (F8TBT) as electron acceptor. Heterojunctions with feature sizes on the order of the exciton diffusion length were reported. The smallest feature sizes are as small as $25 \mathrm{~nm}$ on a $50 \mathrm{~nm}$ pitch. SANIL was used together with a novel double imprint process: After imprinting the surface of P3HT with a silicon stamp, it is sandwiched together with a Kapton/Al/F8TBT system. This method is suitable only for polymer combinations with a large difference in glass transition temperature $T_{g}$, otherwise, polymer deformation would occur at the interface. The technique allows the fabrication of a functional photovoltaic device with precisely defined interfacial geometry.

AFM and SEM images revealed a high quality, defect-free replication of the pattern and it could be conclusively shown that the double imprint technique works. An increase in crystallinity induced by the confinement during the NIL is postulated, which was supported by an increase of the absorption of 
the imprinted compared to the untreated film. This was in good agreement with the overall increase of the device performance, attributed to an increase in the dissociation efficiency, caused by higher mobilites. Photoluminescence (PL) measurements showed a significant quenching and a decrease of (PL) intensity as the pattern feature size was decreased. The authors claimed that by changing the imprint pattern, double imprinting has the potential to allow the dimensions of both phases to be independently tailored to match the respective exciton diffusion length in either phase - a great benefit compared to the bulkheterojuncion (BHJ) solar cell approach. The $\mathrm{V}_{\mathrm{OC}}$ is slightly increasing with smaller feature sizes and short circuit current increases proportional to the additional surface. Interestingly, one can observe an increase in FF from 0.39 to 0.49 when going from 200 to $25 \mathrm{~nm}$ feature sizes, indicating an improved hole mobility and better geminate pair dissociation. The best P3HT/F8TBT device with a nanostructured array exceeded the efficiency of the control blend devices and had an efficiency of $1.9 \%$, an especially impressive result for a polymer-polymer solar cell.

\section{Hybrid Solar Cells}

Another method to control the morphology of the donor-acceptor heterojunction is using highly ordered metal oxide nanostructures. Metal oxides are well known in the field of organic and hybrid photovoltaics. Besides applications as transparent electrodes (indium- or fluorine-doped tin oxide (ITO, FTO)), metal oxides can be employed as electron or hole selective contacts. $\mathrm{ZnO}$ and $\mathrm{TiO}_{2}$ are commonly used as hole-blocking contacts for polymer solar cells. ${ }^{[51,52]}$ In the most widely used cell geometry holes are collected at the front electrode, with low workfunction metals like $\mathrm{Al}$ or $\mathrm{Ca}$ as back electrodes. Since these metals oxidize quickly in air, the resulting solar cells have to be operated in vacuum or inert atmosphere. Electron-selective front contacts allow the usage of noble metal back electrodes in so-called inverted solar cells. ${ }^{[53]}$ Thus, long-term air stable solar cells can be realized. ${ }^{[54,55]}$ Other metal oxides, such as $\mathrm{MoO}_{3}$ or $\mathrm{V}_{2} \mathrm{O}_{5}$, exhibit excellent electron-blocking properties allowing the fabrication of devices with two highly selective contacts. ${ }^{[56,57]}$

Here, we focus on HSCs with ordered nanostructured metal oxides. HSCs are excitonic solar cells and typically consist of at least one absorbing material, e.g., a dye, and a metal oxide with a large surface area. ${ }^{[58]}$ The most common materials for n-type nanostructures are $\mathrm{ZnO}$ and $\mathrm{TiO}_{2}$. Excitons generated in the dye are dissociated at the organic-metal oxide interface with electrons being rapidly injected into the metal oxide..$^{[1]}$ The dye is then regenerated by either a liquid electrolyte, like in DSSCs, ${ }^{[4]}$ or by a solid hole conductor. ${ }^{[59]}$ Currently, liquid electrolyte cells exhibit the highest power conversion efficiencies. However, especially for SS-DSSC, further improvements in device performance are conceivable using highly ordered metal oxides. Ordered structures can be fabricated with large surface areas and can provide pathways for 1D charge transport, thus increasing electron lifetimes and reducing recombination. ${ }^{[60]}$

The incorporation of absorbing hole-transporting conjugated polymers such as P3HT or MDMO-PPV instead of transparent hole conductors in hybrid devices has shown great promise..$^{[61,62]}$
The combination of dye-sensitized nanostructured metal oxides with absorbing polymers enables enhanced light harvesting if the dye absorption is complementary to that of the polymer. ${ }^{[63]}$ Due to flexible fabrication methods of metal oxide nanostructures, the structure and dimension can be controlled on the $\mathrm{nm}$ scale to match the exciton diffusion length of typical photoactive organic materials. Therefore, exciton dissociation efficiencies comparable to fully organic bulk heterojunction solar cells (BHJ) could be reached. BHJ solar cells already exhibit high efficiencies above $7 \%{ }^{[64]}$ However, the donor-acceptor morphology, which plays a crucial role.for mechanisms of charge separation, transport and recombination, cannot be controlled directly in these devices. By replacing the organic acceptor with ordered metal oxide structures, the active layer morphology can be controlled on the nm scale. Percolating pathways for separated charges can be therefore ensured, as well as sufficiently large donor-acceptor interfaces.

An additional benefit of HSCs is the potentially higher device lifetime. Stability of non-Si based solar cells will become an important issue for commercialization. ${ }^{[65]}$ Metal oxides are considered as stable materials compared to organic compounds, which can be degraded by elevated temperatures and exposure to oxygen ${ }^{[66]}$ or water vapor. ${ }^{[67]} \mathrm{UV}$ light is also known to damage organic materials. ${ }^{[68]}$ Since $\mathrm{ZnO}$ and $\mathrm{TiO}_{2}$ exhibit pronounced absorption in the UV range, they can act as UV filters for the organic material in the hybrid cell thus protecting the more sensitive part of the device. However, to date there have been no systematic studies concerning the stability of hybrid solar cells. Such research is required to rigorously demonstrate a higher intrinsic stability in HSC over fully organic solar cells.

\subsection{Unordered Structures and Metal Oxide-Polymer Blends}

In this review we mainly discuss ordered nanostructures. However, this section briefly addresses hybrid solar cells with less ordered active layers.

One approach is the use of mesoporous metal oxide electrodes, usually $\mathrm{TiO}_{2}$, in SS-DSSC, as first employed in liquid electrolyte DSSC. These structures consist of sol-gel processed nanoparticles of 10-30 $\mathrm{nm}$ diameter that are sintered together and form a structure of around $60 \%$ porosity and a 100 -fold increased surface area compared to a flat film. Due to the sintering, mesoporous $\mathrm{TiO}_{2}$ is electronically connected and allows efficient electron transport. In SS-DSSC the mesoporous layer is commonly a few micrometers in thickness to provide sufficient absorption of the dye monolayer which is adsorbed to the $\mathrm{TiO}_{2}$. The structure is infiltrated with a transparent hole conductor such as Spiro-OMeTAD $\left(2,2^{\prime}, 7,7^{\prime}\right.$-tetrakis-( $N, N$-di-pmethoxyphenylamine) $9,9^{\prime}$-spirobifluorene).

Efficiencies of SS-DSSC with mesoporous $\mathrm{TiO}_{2}$ are still around $5 \%$, significantly lower than their liquid electrolyte counterparts. ${ }^{[69,70]}$ Therefore, the use of mesoporous $\mathrm{TiO}_{2}$ in combination with conjugated polymers as hole-conductors instead of the commonly used Spiro-MeOTAD has been considered in order to achieve enhanced light harvesting. ${ }^{\text {[11] }}$ Coakley and McGehee reported remarkable efficiencies of $1.5 \%$ for TiO2-P3HT HSCs in 2003. ${ }^{[72]}$ Further improvements were possible by using additives such as 4 -tert-butylpyridine (TBP) 
and lithium salts which are known to enhance $I_{\mathrm{SC}}, V_{\mathrm{OC}}$, and the power conversion efficiency. ${ }^{[3]}$ Optimized processing and a highly absorbing metal-free dye recently allowed the fabrication of mesoporous $\mathrm{TiO}_{2}$-P3HT HSCs with efficiencies above $2.5 \%$ as reported by $\mathrm{Zhu}$ et $\mathrm{al}^{\left[{ }^{[7]}\right]}$ This is the highest reported efficiency so far for this geometry.

HSCs with an unordered active layer have also been fabricated via an approach similar to organic BHJ solar cells. By blending metal oxide nanoparticles with conjugated polymers, a hybrid active layer can be solution processed. In contrast to infiltration of organics into nanostructures, a complete filling and an improved inorganic-organic contact can be guaranteed. ${ }^{[75]}$ Best efficiencies for hybrid blends have been shown with $\mathrm{PbS}$ or CdSe nanoparticles. In 2002 Huynh et al. reported 1.7\% efficient devices ${ }^{[76]}$ using CdSe and P3HT. However, in contrast to metal oxides such as $\mathrm{TiO}_{2}$ or $\mathrm{ZnO}$, these materials contain toxic compounds such as $\mathrm{Cd}$ or $\mathrm{Pb}$. Beek et al. reported efficiencies of $1.4 \%$ and $0.9 \%$ for blends of $\mathrm{ZnO}$ nanoparticles and MDMO-PPV ${ }^{[61]}$ or $\mathrm{P} 3 \mathrm{HT},{ }^{[77]}$ respectively. Lower performances are reported for blends of surface treated $\mathrm{TiO}_{2}$ nanorods and P3HT: ${ }^{[78]}$ Although the metal oxide's electronic properties and crystallinity can be better controlled in this approach, the insufficient connection between nanoparticles and uncontrolled morphology of the blend lead to trapped charges and low photocurrents.

\subsection{Nanowires}

As discussed above, the ideal morphology for excitonic solar cells is still unknown. However, the interpenetrating donoracceptor interfaces and directed charge transport pathways present in metal oxide nanostructure-based HSCs are considered to conducive to efficient exciton separation and charge transport. Metal oxide nanowires exhibit excellent regularity, orientation and crystallinity properties and can be grown several micrometer long on conducting glass. Application of metal oxide nanowires for energy conversion is also summarized in the review by Hochbaum and Yang. ${ }^{[79]}$

$\mathrm{TiO}_{2}$ nanowires are fabricated in a so-called hydrothermal process. ${ }^{[80]}$ The resulting wires are rutile single crystals and therefore provide excellent electron percolation pathways. In liquid electrolyte DSSC these structures showed impressive efficiencies of $6.9 \%$ for $33 \mu \mathrm{m}$ long wires. ${ }^{[81]}$ Even structures of only $2-3 \mu \mathrm{m}$ length showed efficiencies of $5 \% \cdot{ }^{[82]}$ Since the $\mathrm{TiO}_{2}$ surface area is much smaller in these structures than in $\sim 10 \mu \mathrm{m}$ thick mesoporous $\mathrm{TiO}_{2}$ as commonly used in liquid electrolyte DSSCs, this is a striking hint that the superior charge transport properties of $\mathrm{TiO}_{2}$ wires allow high electron mobilities, ideal percolation pathways and accordingly highly efficient solar cells.

Hydrothermal growth of $\mathrm{TiO}_{2}$ nanowires also facilitates homogeneous doping of the metal oxide. Since the growth is a self-organized process at equilibrium conditions, dopants can be easily added to the hydrothermal bath. Feng et al. reported a $15 \%$ increase of the $V_{\mathrm{OC}}$ in DSSC due to Ta doping of $\mathrm{TiO}_{2}$ nanowires. The achieved $V_{\mathrm{OC}}$ of $0.87 \mathrm{~V}$ is close to the theoretical maximum, showing that optimized metal oxide wires exhibit almost loss-free electron transport. ${ }^{[83]}$
To date there are only very limited studies on HSCs composed of single crystalline $\mathrm{TiO}_{2}$ nanowires and conjugated polymers. The electronic properties of rutile $\mathrm{TiO}_{2}$ are considered to be less favorable for this type of solar cell than anatase $\mathrm{TiO}_{2}$. Therefore, rutile single crystal $\mathrm{TiO}_{2}$ nanowires demand surface treatments or core-shell structures as discussed in Section 3.4. Ensuring that the $\mathrm{TiO}_{2}$ nanowire matrix is completely filled with the hole-conducting material presents a challenge to device fabrication. Currently we are able to almost completely fill the voids of arrays of $1 \mu \mathrm{m}$ long $\mathrm{TiO}_{2}$ wires on FTO with P3HT (see Figure 4), which is a first important step towards efficient HSCs. However, the growth of single crystalline $\mathrm{TiO}_{2}$ wires on a compact $\mathrm{TiO}_{2}$ layer is still complicated. Such a dense layer is necessary to ensure that the front contact is electronselective and to avoid recombination at the P3HT-FTO interface. Additionally, initial experiments with HCSs reveal that elaborate engineering of the $\mathrm{TiO}_{2}$ - $\mathrm{P} 3 \mathrm{HT}$ interface is necessary to avoid charge carrier recombination and allow reasonable FF, $V_{\mathrm{OC}}$ and $I_{\mathrm{SC}}$.

Besides hydrothermal synthesis, template-assisted fabrication methods for $\mathrm{TiO}_{2}$ nanowires are also possible. Kuo et al. reported $\mathrm{TiO}_{2}$-P3HT HSCs from AAO-directed $\mathrm{TiO}_{2}$ nanowires. ${ }^{[84]}$ Here, AAO is fabricated via the anodization of $200 \mathrm{~nm}$ thick Al films that are evaporated directly on ITO. $\mathrm{TiO}_{2}$ is then deposited using a sol-gel method. After heat curing, the $\mathrm{AAO}$ is removed yielding free standing $\mathrm{TiO}_{2}$ nanowires. Compared to flat $\mathrm{TiO}_{2}$ films a significantly increased $I_{\mathrm{SC}}$ is observed, which can be attributed to the larger donor-acceptor interface. However, between the nanowires, ITO is directly exposed to the P3HT. Since ITO effectively collects both electrons and holes, this causes pronounced charge carrier recombination in the nanostructure cell compared to the flat junction device which is reflected in the lower $V_{\mathrm{OC}}$ and the apparently low shunt resistance. The highest efficiency so far for $\mathrm{TiO}_{2}$ nanowires-P3HT solar cells have been reported by Williamson et al. Wires were fabricated via sol-gel deposition onto nanosphere lithography templates. Structures of 30 to $100 \mathrm{~nm}$ in height and 30 to $65 \mathrm{~nm}$ in spacing filled with P3HT resulted in power conversion efficiencies of up to $0.6 \%$. ${ }^{[85]}$

Another approach for $\mathrm{TiO}_{2}$ nanowire fabrication is to electrochemically deposit $\mathrm{TiO}_{2}$ from a $\mathrm{TiCl}_{3}$ precursor into AAO templates, as opposed to the above sol-gel deposition method.

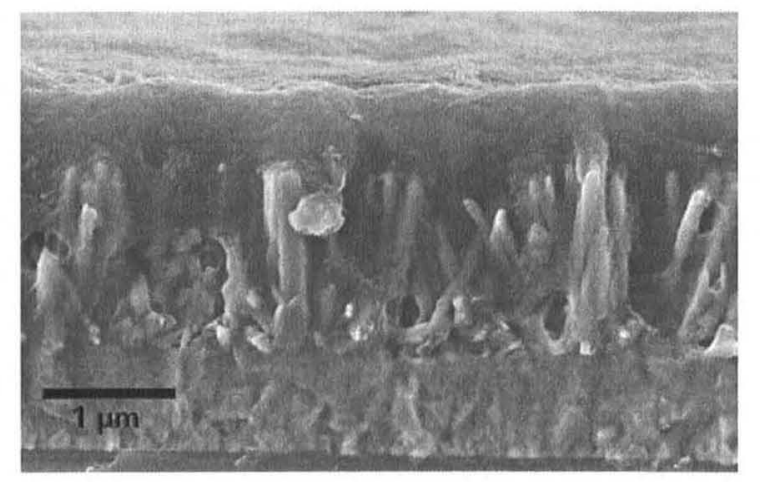

Figure 4. SEM cross-sectional view of $\mathrm{P} 3 \mathrm{HT}$ infiltrated into $\mathrm{TiO}_{2}$ nanowires on FTO coated glass. The filling is almost complete. 


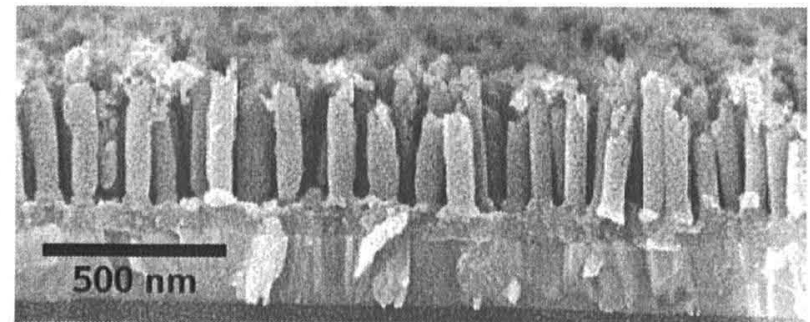

Figure 5. SEM cross-sectional view of $\mathrm{TiO}_{2}$ nanowires grown from electrodeposition onto $\mathrm{AAO}$. The wires are free standing on a compact $\mathrm{TiO}_{2}$ layer on ITO.

This was described by Musselman et al. for AAOs on ITO using thin $\mathrm{Ti}$ and $\mathrm{W}$ layers between the ITO and the $\mathrm{Al}$ as blocking and adhesion layers, respectively. ${ }^{[86]}$ Recently, we optimized the synthesis of $\mathrm{TiO}_{2}$ nanowires following this method (Figure 5). It is possible to fabricate free standing $\mathrm{TiO}_{2}$ nanowires directly on a compact layer of $\mathrm{TiO}_{2}$, which functions as an anodization blocking layer as well as an $\mathrm{Al}$ adhesion layer. The length and diameter of the wires can be controlled via the AAO template and aspect ratios of 1:6 have been realized. TEM studies reveal that after heat curing at $450{ }^{\circ} \mathrm{C}$ these wires are polycrystalline anatase $\mathrm{TiO}_{2}$.

Extensive studies have also been carried out on $\mathrm{ZnO}$, another promising material for the fabrication of $n$-type nanowires for HSCs. Some recent results are summarized in the review article by Gonzales-Valls and Lira-Cantu. ${ }^{[87]}$ Similar to $\mathrm{TiO}_{2}, \mathrm{ZnO}$ nanowires can be easily grown using hydrothermal methods. For $\mathrm{ZnO}$ nanowires, the fabrication commonly consists of two steps. First, a seed layer is formed from $\mathrm{ZnO}$ nanoparticles of approximately $10 \mathrm{~nm}$ diameter. These particles work as nucleation sites for wire growth, which is carried out in the second step. ${ }^{[88]}$ By choosing appropriate synthesis conditions, control of quality and dimensions of the wires is possible. $\mathrm{ZnO}$ nanowires are usually grown at temperatures below $100{ }^{\circ} \mathrm{C}$ making them interesting for low-cost mass production. ${ }^{[89]}$

Generally, HSCs based on $\mathrm{ZnO}$ nanowires show relatively low performances at present. Law et al. reported efficiencies of $1.5 \%$ for liquid electrolyte DSSC based on $\mathrm{ZnO}$ nanowires in $2005 .{ }^{[90]}$ It is likely that the lower efficiency compared to conventional DSSCs based on mesoporous metal is due to their reduced interfacial area. However, as outlined by Law and co-workers, $\mathrm{ZnO}$ nanowires offer the potential to achieve almost loss-free electron transport. When comparing $\mathrm{ZnO}$ and $\mathrm{TiO}_{2}$ nanoparticle cells exhibiting different layer thicknesses and roughness factors with $\mathrm{ZnO}$ nanowire devices, the $I_{\mathrm{SC}}$ is found to increase linearly with the metal oxide surface area for ordered structures. In contrast, for nanoparticle cells, insufficient charge transport seems to limit the device performance above a certain layer thickness.

Devices composed of $\mathrm{ZnO}$ nanowires and conjugated polymers such as P3HT have demonstrated efficiencies between $0.2 \%$ and $0.5 \% .^{[11-93]}$ It has only been possible to increase the efficiency of these devices (up to $3 \%$ ) through the addition of an organic acceptor such as PCBM. ${ }^{[94,95]}$ However, this is not considered to be an intrinsic drawback of $\mathrm{ZnO}$ nanowires, which exhibit beneficial crystallinity and high electron mobility. To date, dimensions of $\mathrm{ZnO}$ nanowires are not completely optimized. Nanowire arrays show relatively large wire spacing and diameters resulting in lower surface area compared to mesoporous structures. Since the dimensions do not match the exciton diffusion length of typical organic donors, geminate recombination is a severe problem of recent $\mathrm{ZnO}$ nanowire arrays. More advanced surface engineering is necessary to enhance $V_{O C}$ in HSCs based on $\mathrm{ZnO}$ nanowires. Growing attention is paid to core-shell structures as discussed in Section 3.4.

Another interesting approach to study the properties of $\mathrm{ZnO}$ nanowires has been recently presented by Briseno and coworkers. ${ }^{[96]}$ By grafting modified P3HT to $\mathrm{ZnO}$ nanowires they were able to realize single nanowire cells. Detailed analysis of such structures might allow insight to principle working mechanisms of ZnO-based HSCs and could reveal design rules for improved devices.

Currently, there are only very limited studies on metal oxide nanowires of materials different than $\mathrm{TiO}_{2}$ or $\mathrm{ZnO}$. Schwenzer et al. reported on HSCs composed of p-type nanowires of $\mathrm{Co}_{5}(\mathrm{OH})_{8}\left(\mathrm{NO}_{3}\right)_{2} \cdot 2 \mathrm{H}_{2} \mathrm{O}$ and the n-type polymer poly(3-butylthiophene) (P3BT) $\cdot{ }^{\left[{ }^{27]}\right.}$ Although these devices exhibit a low FF of $26 \%$ and $I_{\mathrm{SC}}$ of $9 \mu \mathrm{A} / \mathrm{cm}^{2}$, a $V_{\mathrm{OC}}$ of $1.38 \mathrm{~V}$ can be measured, very close to the theoretical maximum. Recently, Yu et co-workers showed that ITO nanowires efficiently enhance the hole transport in polymer-fullerene BHJ. Incorporation of $100 \mathrm{~nm}$ long structures yielded efficiency improvements of $10 \%$ and $34 \%$ under simulated one sun and five suns illumination, respectively. Especially at high illumination intensities, the improved hole extraction has a significant impact on the device performance.

\subsection{Nanotubes}

A geometry which has generated remarkable scientific interest during the past years is the nanotube array. Similar to nanowires, tubular structures provide excellent pathways for directed charge transport. In addition, nanotubes exhibit almost twice the surface area as rod-like structures of similar dimensions. This makes metal oxide nanotubes especially interesting for application in HSCs, where large surface areas for dye adsorption and large donor-acceptor interfaces are demanded.

By far the most common metal oxide for tubular structures is $\mathrm{TiO}_{2}$. Progress in the field of these structures is summarized in the reviews of Mor et al. ${ }^{[98]}$ and Ghicov and Schmuki. ${ }^{[9]}$ Utilizing self-organization processes, $\mathrm{TiO}_{2}$ nanotubes are usually formed by anodization of metallic Ti in fluoride ion containing electrolytes, either aqueous $\mathrm{HF}$ solutions ${ }^{[100]}$ or $\mathrm{NH}_{4} \mathrm{~F}$ containing ethylene glycol baths. ${ }^{[101]}$ For the latter, $360 \mu \mathrm{m}$ long nanotubes with aspect ratios above 2000 have been realized when anodizing high purity Ti foils. ${ }^{[102]}$ The tubes are hexagonally packed and are forming at growth velocities of $15 \mu \mathrm{m} / \mathrm{h}$. $\mathrm{TiO}_{2}$ nanotubes can also be grown directly on transparent conducting glass substrates by sputtering high quality Ti films and subsequent anodization. ${ }^{[103]}$ This offers the advantage that conventional cell geometries with front illumination (through the glass substrate) can be realized, which is especially interesting for solid state HSCs. Paulose et al. reported on backside illuminated DSSC assembled from Ti foils and found a significant loss 
in light intensity and performance due to the partial opaqueness of the Pt covered counter electrodes. ${ }^{[104]}$ By adjusting the anodization process parameters, control over tube length, diameter, wall thickness and spacing can be achieved. ${ }^{[105]}$

Remarkable efficiencies above $6 \%$ have been reported for liquid electrolyte DSSCs based on anodized Ti foils. ${ }^{101,106]}$ Although this is lower than performances of DSSC with mesoporous $\mathrm{TiO}_{2}$ films, tubular structures are considered to offer great potential. Aside from the non-ideal backside illumination, the lower efficiencies are mainly attributed to a lower dye uptake due to the smaller surface area. However, the favorable charge transport properties of ordered tubular structures may give rise to record efficiency DSSCs in the future. In contrast to single crystalline nanowires, nanotubes from anodization of $\mathrm{Ti}$ are polycrystalline with typical grain sizes of $30-40 \mathrm{~nm}$ and have to be annealed at temperatures above $450{ }^{\circ} \mathrm{C}$ to yield anatase crystallinity. ${ }^{[107]}$ Due to crystal domain sizes being only slightly larger than in mesoporous $\mathrm{TiO}_{2}$, only a small difference in the electron mobility is expected. However, ordered structures enhance electron lifetimes due to optimized percolation pathways and therefore reduce recombination losses. Future research may also yield nanotubular structures with enlarged grain size.

One of the most impressive examples of the high potential of $\mathrm{TiO}_{2}$ nanotubes was presented by Mor et al. in 2006.[60] Using only $360 \mathrm{~nm}$ long $\mathrm{TiO}_{2}$ tubes on conducting glass they realized DSSCs with efficiencies of $2.9 \%$ and $I_{\mathrm{SC}}$ of $7.9 \mathrm{~mA} / \mathrm{cm}^{2}$. The overall dye absorption is relatively low in such small structures, which limits the photocurrent. However, the impressive efficiencies could be directly attributed to increased electron lifetimes and optimized transport pathways compared to mesoporous $\mathrm{TiO}_{2}$.

To our knowledge, there are no systematic studies on SSDSSC based on nanotubular $\mathrm{TiO}_{2}$ yet. However, $\mathrm{TiO}_{2}$ nanotubes have been used in highly efficient HSCs with conjugated polymers. In 2009 Mor and co-workers reported on $\mathrm{TiO}_{2}-\mathrm{P} 3 \mathrm{HT}$ HSCs based on nanotubular films of a few $100 \mathrm{~nm}$ on FTO glass. ${ }^{[63]}$ By using a dye with absorption in the near infrared and utilizing nanotube geometries that almost match the exciton diffusion length of P3HT, they were able to achieved efficiencies up to $3.8 \%$, which is the highest performance reported so far for metal oxide-dye-conjugated polymer HSCs. These high efficiencies were possible only after $\mathrm{TiCl}_{4}$ treatment of the nanotubes and the use of TBP. $\mathrm{TiO}_{2}$ nanotube arrays infiltrated with blends of $\mathrm{P} 3 \mathrm{HT}$ and $\mathrm{PC}_{71} \mathrm{BM}$ still show slightly higher efficiencies, suggesting that additional surface engineering and further optimization of the $\mathrm{TiO}_{2}$ geometry is necessary if the organic acceptor is completely replaced by the $\mathrm{TiO}_{2}{ }^{[108]}$

In addition to the anodization of Ti foils, other methods for the fabrication of $\mathrm{TiO}_{2}$ nanotubes are available. Foong and co-workers reported on a template-directed growth of $\mathrm{TiO}_{2}$ nanotubes using atomic layer deposition (ALD) onto AAO membranes. ${ }^{[109]}$ Optimized anodization conditions for AAOs allow the formation of highly ordered hexagonally packed nanostructures ${ }^{[110]}$ Thus, nanotubular $\mathrm{TiO}_{2}$ thin films could be realized in the future. Additionally, ALD allows the fabrication of tubes with small wall thicknesses below $5 \mathrm{~nm}$.

Another interesting method of tube synthesis was presented by $\mathrm{Na}$ et al. in 2008..$^{[11]}$ Via electrodeposition onto ITO, a template of $\mathrm{ZnO}$ nanorods can be fabricated. $\mathrm{TiO}_{2}$ is then deposited onto this template from a sol-gel and undergoes a heat treatment. Finally, the $\mathrm{ZnO}$ is removed, resulting in free standing $\mathrm{TiO}_{2}$ nanotubes on conducting glass. Sol-gel deposition also results in a thin compact $\mathrm{TiO}_{2}$ layer which makes the structures highly interesting for use in HSCs.

Compared to $\mathrm{TiO}_{2}$ there are only very limited studies on nanotubular structures of $\mathrm{ZnO}$. Similar to $\mathrm{TiO}_{2}$, nanotubes are fabricated via self-organization processes. Using a low temperature liquid phase method, hexagonal $\mathrm{ZnO}$ nanotubes have been fabricated on $\mathrm{Zn}$ foil. ${ }^{[112]}$ By choosing appropriate conditions, ultrathin $\mathrm{ZnO}$ nanowires have also been synthesized on a $\mathrm{ZnO}$ compact layer on $\mathrm{Si}$ in a hydrothermal process. ${ }^{[113]}$ Martinson et al. reported on liquid electrolyte DSSC based on $\mathrm{ZnO}$ nanotubes. ${ }^{[14]}$ These structures were fabricated by ALD onto AAO membranes. Even though only moderate efficiencies of $1.6 \%$ have been achieved, their results show that $\mathrm{ZnO}$ nanotubes provide excellent and almost loss-free electron transport over several $\mu \mathrm{m}$.

\subsection{Metal Oxide Modifications and Core-Shell Structures}

Several reports on various systems agree that the interface between donor and acceptor plays a crucial role for processes of charge separation and recombination. The commonly used solution processing for fully organic solar cells does not allow direct control of this interface. In contrast, metal oxide nanostructures can be easily modified in HSCs. Surface treatments, doping and the application of core-shell structures offer the potential to increase charge separation yield, reduce recombination and enhance both $V_{\mathrm{OC}}$ and $I_{\mathrm{SC}}$, resulting in more efficient devices. In addition to the full control of the interface morphology, this is another advantage of HSCs compared to fully organic $\mathrm{BHJ}$.

Usually, all kinds of $\mathrm{TiO}_{2}$ nanostructures show better efficiencies in HSCs after a $\mathrm{TiCl}_{4}$ treatment. ${ }^{[115]} \mathrm{TiCl}_{4}$ is supposed to fill $\mathrm{Ti}$ voids at the $\mathrm{TiO}_{2}$ surface, fill cracks and repair defects. Additionally, a $\mathrm{TiCl}_{4}$ treatment slightly increases the $\mathrm{TiO}_{2}$ surface area yielding a larger interface for dye adsorption.

For mesoporous $\mathrm{TiO}_{2},{ }^{[116]} \mathrm{TiO}_{2}$ nanocrystal bulk heterojunction cells ${ }^{[78]}$ and HSCs based on nanotubular $\mathrm{TiO}_{2},{ }^{[63]}$ it has been shown that the choice of suitable sensitizers can efficiently reduce recombination and improve $V_{\mathrm{OC}}$ and device efficiency. However, the sensitizer materials have to be chosen carefully. Liu et al. were able to change the work function of planar $\mathrm{TiO}_{2}$ by modification with carboxylated polythiophenes and tested the metal oxide's properties in P3HT-based HSCs. ${ }^{[117]}$ Although they could significantly improve the exciton separation yield, interfacial dipoles caused a band offset shift at the metal oxidepolymer junction, reducing the $V_{\mathrm{OC}}$. Surface modifications can also be used to influence the interfacial morphology. Lloyd and co-workers investigated P3HT crystallinity at the heterojunction in ZnO-P3HT HSCs. ${ }^{[118]}$ Untreated $\mathrm{ZnO}$ shows a strong interaction with the P3HT and hinders crystallization of the polymer. However, if $\mathrm{ZnO}$ is modified with an alkanethiol monolayer, the polymer shows enhanced crystallinity in a region extending up to a few $\mathrm{nm}$ from the $\mathrm{ZnO}$ interface, leading to reduced recombination, improved $I_{\mathrm{SC}}$ and efficient solar cells. 
An interesting approach for P3HT-based HSCs is the use of carboxylated polymer dyes based on P3HT. ${ }^{[119]} \mathrm{A}$ monolayer of this polymer dye grafted to the metal oxide surface might work as a crystallization seed layer and induce favorable P3HT alignment along the nanostructure. Due to a similar HOMO and LUMO structure, both efficient energy and charge transfer should be possible between the P3HT and the polymer dye. Another very promising sensitizer for P3HT-metal oxide devices was presented by Vaynzof et al. ${ }^{[120]}$ By covering flat $\mathrm{ZnO}$ films with a carboxylated PCBM they were able to improve the $V_{\mathrm{OC}}, I_{\mathrm{SC}}$ and FF compared to non-modified $\mathrm{ZnO}$. Since the combination of P3HT and PCBM is well known to facilitate efficient charge separation, PCBM-based sensitizers might allow high performance HSCs in the future, especially for carboxylated $[6,6]$-phenyl $\mathrm{C}_{70}$-butyric acid methyl ester ( $\left.\mathrm{PC}_{70} \mathrm{BM}\right)$, which shows a broader absorption in the visible spectrum than PCBM. ${ }^{[121]}$

Besides surface modifications, doping of metal oxides is a versatile method to influence charge transport properties and location of valence and conduction band. Olson et al. were able to achieve almost doubled $V_{\mathrm{OC}}$ for ZnO-P3HT hybrid devices by doping $\mathrm{ZnO}$ with $\mathrm{Mg}{ }^{[92]} \mathrm{An}$ alloy of $\mathrm{ZnMgO}$ results in a reduced band offset and therefore allows an increased potential. For $\mathrm{Mg}$ contents between $0 \%$ and $25 \%$ they were able to decrease the effective work function from $-4.2 \mathrm{eV}$ to $-3.9 \mathrm{eV}$ resulting in an increase of $V_{\mathrm{OC}}$ from $0.5 \mathrm{~V}$ to more than $0.9 \mathrm{~V}$. As mentioned above, similar effects have been reported for $\mathrm{TiO}_{2}$ doped with $\mathrm{Ta}^{[83]}$ or $\mathrm{N}^{\left[{ }^{[122]}\right.}$ For N-doping, Vitiello et al. were also able to show enhanced photoactivity of $\mathrm{TiO}_{2}$ nanotubes in the visible range. ${ }^{[123]}$

To simultaneously optimize both surface of the metal oxide and charge transport properties of the nanostructure, coreshell morphologies have been considered. Metal oxide nanostructures are coated with a thin layer of another material thus combining high mobility of the inner material with high charge selectivity of the coating.

Law et al. reported liquid electrolyte DSSCs featuring coated $\mathrm{ZnO}$ nanowires. ${ }^{[124]}$ Comparing different thicknesses of ALD coatings with $\mathrm{Al}_{2} \mathrm{O}_{3}$ and $\mathrm{TiO}_{2}$, they present a pathway towards highly efficient DSSCs. Both materials reduce recombination since the back-transfer of electrons from the $\mathrm{ZnO}$ into the dye is hindered. However, improved performances were only found for $\mathrm{TiO}_{2}$. As an insulator, $\mathrm{Al}_{2} \mathrm{O}_{3}$ reduces the probability of electrons tunneling in both directions, towards the $\mathrm{ZnO}$ and the dye. In contrast, due to excellent hole-blocking properties in combination with high electron mobilities, $\mathrm{TiO}_{2}$ coatings help to transfer electrons from the dye to the $\mathrm{ZnO}$ by simultaneously constraining the back-reaction.

$\mathrm{ZnO}-\mathrm{TiO}_{2}$ core-shell structures have also been applied in P3HT-based HSCs. Greene and co-workers reported on ALD coatings of $\mathrm{ZnO}$ nanowires with $\mathrm{TiO}_{2}{ }^{[125]}$ Even though the overall efficiencies are relatively low and do not exceed $0.3 \%$ in this study, they were able to show a six-fold increase in performance for $\mathrm{TiO}_{2}$-coated nanowires. This is especially remarkable when considering that no dye was used in this work.

Recently, Hao et al. reported on an interesting system of twoshell nanowires. ${ }^{[126]}$ By subsequent electrodeposition of CdSe and thiophenes onto $\mathrm{ZnO}$ nanowires, they were able to significantly improve the performance of liquid electrolyte DSSCs compared to $\mathrm{ZnO}$-CdSe core-shell structures. Additional charge carriers are generated at the P3HT-CdSe p-n junction and broadening of the absorption spectrum due to P3HT lead to significantly higher $I_{\mathrm{SC}}$ and even slightly increased $V_{\mathrm{OC}}$

\subsection{Working Mechanisms in HSCs}

With the growing interest in the field of HSCs, a lot of effort has been put on synthesis and characterization of nanostructured metal oxides. However, there are still many open questions. The ideal donor-acceptor morphology is unknown, although there are hints that ordered nanostructures providing huge interfaces and 1D charge percolation pathways can come close to the optimum in terms of exciton separation and charge transport. Besides, the impact of metal oxide crystallinity and grain size is not yet completely analyzed. In solid state HSCs ordered metal oxide nanostructures offer the additional advantage that also hole transport in the organic material can be improved. Organics infiltrated into the nanostructure do as well provide continuous pathways for charge transport. Additionally, confinement in nano-cavities can induce alignment of organic molecules which further enhances the hole mobility.

\subsubsection{Absorption and Exciton Separation}

High photovoltaic performances demand high absorption over a broad range of the solar spectrum. Dye-based solar cells such as DSSC and other HSCs offer the advantage of a tunable absorption band through the choice of dye. However, since dyes are applied only as monolayers, relatively thick active layers are necessary if the dye is the sole absorber. Currently, sufficiently thick layers of alternative absorbing material can be realized only in liquid electrolyte DSSCs and not in their solid state counterparts. Here, the active layer thickness is limited to a few micrometers, mainly due to insufficient filling and non-ideal hole transport. ${ }^{[11]}$ Nevertheless, SS-DSSCs are an interesting alternative to conventional DSSCs since no toxic electrolyte is necessary and flexible devices can be realized. ${ }^{[127]}$ In addition, SS-DSSC can already compete with fully organic solar cells and unlike conventional DSSCs, the coloring of the cells can be arbitrarily tuned via the dye, which could be interesting for commercial applications.

By using conjugated polymers such as P3HT instead of a transparent hole conductor, enhanced device absorption is pos sible also for sub-micrometer active layers. ${ }^{[63]}$ However, metal oxide geometries still have to be improved to better meet the exciton diffusion length in polymers. Further optimization of the organic-inorganic interface is necessary to guarantee efficient charge separation. The ideal combination of materials is still unknown and possibly new dyes have to be developed to allow loss-free charge and energy transfer from the polymer. To date, most reports focus on well-known polymers such as P3HT and MDMO-PPV. In fully organic solar cells, new types of polymers have been recently presented and allowed power conversion efficiencies above $7 \%{ }^{[64]}$ These polymers exhibit broad absorption spectra, optimized HOMO and LUMO levels and high hole mobilities. Accordingly, these materials might also be highly interesting for applications in conjugated polymer-based HSCs. 
Once the absorption is optimized and donor-acceptor distances are in the range of typical exciton diffusion lengths, highly efficient charge separation is demanded. For dyes on metal oxides the mechanism of electron injection is relatively well understood. Covalent binding between the dye-linker and the metal oxide ensures good electrical contact across the interface and allows efficient charge injection. A sophisticated approach is the development of "push-pull" dyes, which further increase the probability of electron injection by simultaneously reducing recombination. ${ }^{[128,129]}$ In these dyes, HOMO and LUMO states are spatially separated. The LUMO is located close to the inorganic-organic interface whereas the HOMO is spaced further away from the metal oxide. This enhances the injection of electrons, suppresses recombination by pushing electrons and holes away from each other and accelerates the regeneration of the dye, i.e. the transfer of holes to the electrolyte or the organic hole conductor. ${ }^{[130,131]}$

In contrast, there are still many open questions concerning the P3HT-metal oxide (dye-coated or neat) interface. Generally, an energy level cascade from the P3HT towards the metal oxide is considered ideal for charge separation. ${ }^{[63]}$ Provided the energy level differences between dye and metal oxide are in the range of exciton binding energies, charge separation may occur as discussed above. Additionally, free charges can be yielded at the interface of the P3HT and the dye or the metal oxide. The resulting $V_{\mathrm{OC}}$ is determined by the metal oxide's quasi-Fermi level and the HOMO of the P3HT. However, if charge recombination is efficiently suppressed due to surface coatings, e.g., $\mathrm{Al}_{2} \mathrm{O}_{3}$, or if the dye sufficiently screens electrons in the metal oxide and holes in the P3HT, $V_{\mathrm{OC}}$ enhancements can be realized. For the case where the HOMO and LUMO levels in the dye and in P3HT match, energy as well as charge transfer is conceivable. Excitons might thus travel through the polymer matrix towards the dye-metal oxide interface where they get separated. The resulting $V_{O C}$ is then understood to be independent of the hole conductor and should be similar e.g. for P3HT and Spiro-OMeTAD.

\subsubsection{Charge Transport}

Although widely investigated, the mechanism of electron transport through nanostructured $\mathrm{ZnO}$ or $\mathrm{TiO}_{2}$ is still not yet fully understood. However, it is undisputed that charge transport is many orders of magnitude faster in single crystals than in polycrystalline structures, which implies an intrinsic limitation for mesoporous metal oxides. Charge mobilities are considered to be relatively similar for $\mathrm{ZnO}$ and $\mathrm{TiO}_{2}$ structures. Quintana et al. reported comparable findings for mesoporous $\mathrm{ZnO}$ and $\mathrm{TiO}_{2}$ with $15 \mathrm{~nm}$ particle sizes in liquid electrolyte DSSCs. ${ }^{[132]}$ They also found significantly longer electron lifetimes but lower cell performance for $\mathrm{ZnO}$, suggesting differences in charge injection and back-reaction for these two materials.

For $\mathrm{TiO}_{2}$, charge transport is mainly hindered across grain boundaries ${ }^{[133]}$ and at the surface of structures and particles. ${ }^{[134,135]}$ This is attributed to a higher density of trap states at these locations. There is convincing evidence that electron transport in $\mathrm{TiO}_{2}$ is determined by trapping and detrapping between sub-bandgap states in the tail of the density of states and the conduction band ${ }^{[136,137]}$ as covered by the multiple-trapping model. ${ }^{[138,139]}$ As discussed in a previous report ${ }^{[11]}$ it is hard to exactly determine the location of trap states. However, it is relatively obvious that single crystalline structures and structures with larger grains exhibit less trap states and accordingly higher electron mobilities and lifetimes. Upon variation of the crystal domain size via different annealing treatments in mesoporous $\mathrm{TiO}_{2}$-based SS-DSSCs, a direct dependence of grain size and photocurrent is found. ${ }^{[140]}$ This suggests that improving the electron transport properties of metal oxides is a promising pathway towards higher efficiencies for HSCs.

Our recent work provides hints that the domain size is significantly larger in our $\mathrm{TiO}_{2}$ nanotubular structures compared to mesoporous layers. By carefully adjusting the appropriate anodization conditions, partial control over grain structure and domain size during the anodization process might be possible.

Impressive charge carrier mobilites of $1 \mathrm{~cm}^{2} \mathrm{~V}^{-1} \mathrm{~s}^{-1}$ have been reported for single crystals, especially for rutile $\mathrm{TiO}_{2}$. Hendry and co-workers directly compared commercially available rutile single crystals with several micrometer-thick mesoporous layers. ${ }^{[141]}$ Using terahertz time domain spectroscopy they found 1000-fold increased electron mobility in the single crystal compared to the nanocomposite film. As discussed above, single crystal rutile nanowires, promising similarly high mobilities, can be grown for applications in HSCs. Although advanced surface engineering is necessary for solid state HSCs due to the non-ideal band structure of rutile $\mathrm{TiO}_{2}$, the beneficial charge transport properties make rutile $\mathrm{TiO}_{2}$ nanostructures appealing candidates for incorporation into future high-performance HSCs.

Balanced, non-dispersive charge transport is considered advantageous for excitonic solar cells. ${ }^{[142]}$ Ordered metal oxide nanostructures offer the potential to not only improve electron transport but also allow higher hole mobilities. Infiltration of organic materials in 1D ordered nanostructures guarantees continuous, defect-free pathways for hole transport thus increasing overall mobilities and reducing recombination.

In the case of Spiro-OMeTAD, the hole transport is quite well understood. Charges travel via polaron hopping between molecular sites with an approximate mobility of $10^{-4} \mathrm{~cm}^{2} \mathrm{~V}^{-1} \mathrm{~s}^{-1}$ in the pristine material. ${ }^{[143]}$ Commonly, additives are used to further increase the hole mobility. Using bis(trifluoromethylsulfonyl) amine lithium salt (Li-TFSI) as an additive, a 10-fold increase in mobility has been realized. ${ }^{[144]}$ Thus, the hole mobility becomes comparable to the electron mobility in mesoporous $\mathrm{TiO}_{2}$. However, the thickness of SS-DSSCs still seems to be limited compared to liquid electrolyte DSSCs due to the different hole transport mechanisms. ${ }^{[145]}$

As mentioned above, conjugated polymers as hole conductors are a promising approach for high efficiency solid state HSCs with thin active layers due to the achievable high absorption coefficients. In the case of P3HT, ordered nanostructures offer the additional benefit of improved hole transport. Besides the provided continuous pathways, ordered structures can induce favorable alignment of the P3HT. P3HT assembles to sheet-like structures with three possible orientations on the substrate (edge on, face on and vertical, see Figure 6.) and different resulting charge transport directions ${ }^{[146]}$ : 1) along the polymer backbone, 2) along the $\pi-\pi$ stacking direction, i.e., 


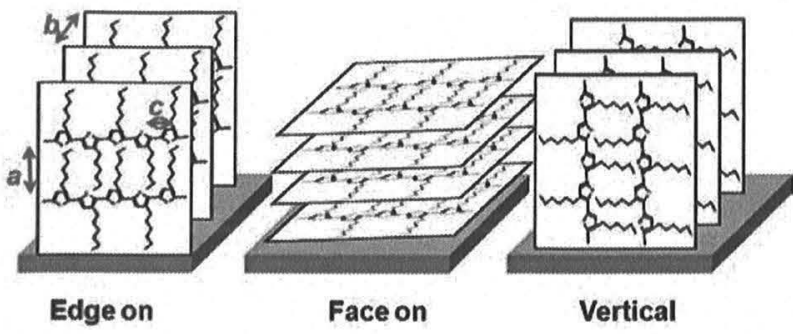

Figure 6. Possible P3HT orientations on a substrate (taken from). Charge mobilities are highest along the polymer backbone, direction c, moderate between sheets, direction $b$, and lowest across the side chains, direction a. Adapted with permission. ${ }^{[146]}$ Copyright 2009, American Chemical Society.

from one sheet to another and 3) across the side chains. Hole mobilities are highest in case 1) and lowest in case 3). ${ }^{[147,148]}$ In $\mathrm{BHJ}$, the orientation is supposed to be mainly edge on, i.e., less beneficial in terms of hole mobility. However, the desired vertical orientation could be realized in HSCs utilizing ordered nanostructures. Aryal et al. reported vertical alignment of P3HT in nano-cavities. ${ }^{[146]}$ When imprinting edge-on oriented P3HT films with nanopores or nanogratings, they were able to change the orientation of the polymer. Infiltration of polymer into nanostructures leads to a similar effect resulting in the P3HT backbone oriented along the z-axis, which should provide excellent mobilities towards the hole-collecting electrode.

An additional effect caused by ordered nanostructures is a beneficial screening of holes, which further increases the mobility. Coakley et al. investigated the mobility of P3HT infiltrated into AAO templates. ${ }^{[149]}$ Besides beneficial alignment effects they found an additionally increased mobility due to a modified hole density. Since the AAO screens holes in neighboring nanopores, holes in the same pore repel each other resulting in high densities close to the metal oxide. Figure 7 depicts the resulting model suggested for hole transport in P3HT-based HSCs with ordered nanostructures. Confinement inside the nanostructure leads to vertically oriented P3HT. High order is present mainly close-by the side walls of the metal oxide, whereas less ordered domains are located further away from the nanostructure. Due
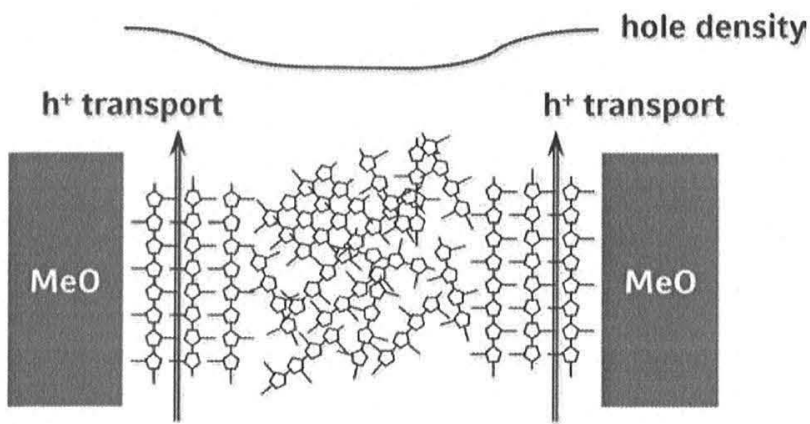

Figure 7. Suggested model for the hole transport in P3HT-based HSCs. $\mathrm{P} 3 \mathrm{HT}$ is vertically aligned with respect to the substrate, expecially close-by the side walls of the metal oxide $(\mathrm{MeO})$ nanostructure. Due to screening effects the hole density is higher in the regions of highly oriented P3HT resulting in further increased mobilites. to screening of holes in neighboring cavities, the hole density is increased especially in regions of high P3HT order and pronounced vertical orientation. Thus, structures with superior hole mobility can be realized.

We note that similar to the screening of holes by metal oxides, the P3HT might screen electrons in neighboring nanorods or -tubes resulting in both high electron and hole density close to the inorganic-organic interface. This might lead to enhanced recombination demanding for sophisticated surface engineering.

\subsubsection{Charge Recombination}

Besides exciton recombination, charge carrier recombination is one of the crucial loss mechanisms in organic and hybrid solar cells. The recombination of separated electrons and holes lowers $V_{\mathrm{OC}}$ and $I_{\mathrm{SC}}$ and causes shunts, which also reduce the FF. Avoiding recombination is an important prerequisite for high efficiency excitonic solar cells.

In dye-based solar cells the dye plays an important role in the mechanism of recombination. If an electron is injected into the metal oxide and the dye is rapidly regenerated, extraordinarily slow charge carrier recombination in the order of tens of milliseconds is present in liquid electrolyte DSSC..$^{[1]}$ For these devices this is attributed to a rather slow two-electron process of recombination, which is a special property of the commonly used iodide/triiodide system. ${ }^{[150,151]}$ However, insufficiently regenerated dye can lead to pronounced recombination. There, after injection of the electron into the metal oxide, the hole is still located in the dye and can easily recombine with an electron.

For solid state hole conductors such as Spiro-OMeTAD or P3HT, regeneration of the dye is typically much faster than for liquid electrolytes and occurs on the nanosecond timescale. However, due to being an one-electron process, recombination is enhanced and takes place within microseconds. ${ }^{[73]} \mathrm{An}$ interesting approach to slow down recombination is the use of donor-acceptor dyads which introduce another energy step between $\mathrm{p}$-type and n-type material. These dyads utilize an electron-donating domain next to the chromophore. ${ }^{[42]}$ Thus, immediately after charge injection into the metal oxide the hole is transferred to this domain before the chromophore is regenerated by the hole conductor. Due to the increased spacing between metal oxide and hole conductor, recombination is significantly slowed down. For liquid electrolyte DSSCs utilizing dyads, recombination times in the order of seconds have been realized. ${ }^{[130]}$

Generally, quick transport of charges away from the interface is considered to reduce recombination losses. For unbalanced charge mobilities and slow transport of one type of carriers, solar cells approach a space charge limited regime. The slower charge carrier is not sufficiently transported away from the interface and a "charge jam" builds up, promoting recombination. ${ }^{[152]}$ On the other hand, if mobilities are too high, the back-transfer of charges towards the interface might also be enhanced.

Core-shell structures seem to offer several advantages for solid state HSCs in terms of recombination and charge transport. Figure 8 shows an idealized structure and the respective 


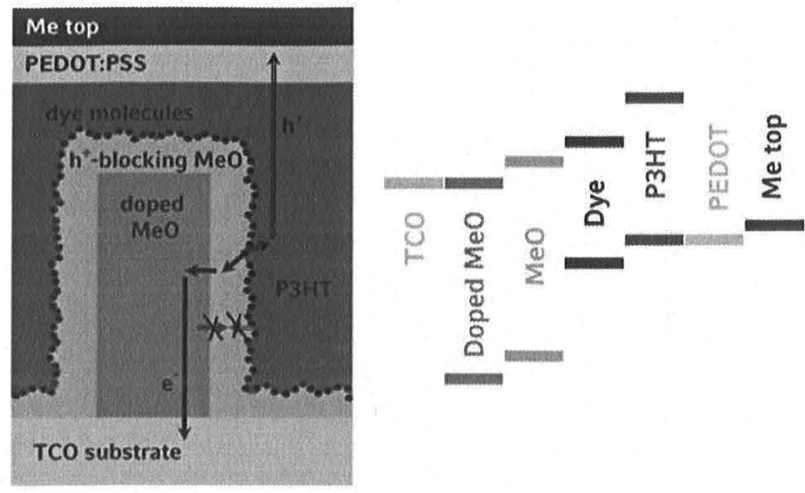

Figure 8. Device geometry and energy diagram for an idealized core-shell metal oxide-P3HT HSC. Excitons are efficiently separated at the inorganicorganic interface and electrons are injected into a thin layer of hole blocking metal oxide $(\mathrm{MeO})$. Subsequently, electrons are transported through a highly doped $\mathrm{MeO}$ exhibiting high mobility whereas holes travel through the polymer and are collected at the opposing metal (Me) electrode. Due to the thin hole blocking $\mathrm{MeO}$ layer and an optimized energy landscape recombination of holes and electrons is sufficiently suppressed.

energy landscape. From our point of view these structures offer the highest potential for a solid state HSCs. Once optimized, such devices might compete with the best fully organic BHJ or even with liquid electrolyte DSSCs.

In this approach, a single crystalline nanowire, e.g. rutile $\mathrm{TiO}_{2}$, is in direct contact with the transparent conductive oxide (TCO) substrate. A thin coating of a second metal oxide such as anatase $\mathrm{TiO}_{2}$ provides excellent hole blocking and exhibits an energetic structure favorable for electron collection. The surface is further treated to enhance the surface area, e.g. with $\mathrm{TiCl}_{4}$, which also reduces the density of surface trap states. The large surface area of the nanostructure is coated with a suited pushpull dye or a dyad, preferably absorbing in the near infrared. Geometries of the nanostructure are around 15 to $20 \mathrm{~nm}$ and match the exciton diffusion length of P3HT, which is vertically aligned with respect to the substrate due to confinement into the nanostructure. Active layer thicknesses are around 1 or $2 \mu \mathrm{m}$ to guarantee sufficient light absorption over a broad spectrum. The solar cell is finalized with a thin layer of PEDOT:PSS, which is well known for its favorable hole-collecting properties, ${ }^{[153]}$ and a reflecting metal back electrode. Adjusted energy levels in such an optimized structure ensure cascades for both electron and hole transport as well as ohmic contacts between the active materials and the external electrodes.

\section{Nanostructures and Light Trapping}

The device nanostructure plays also a critical role in the process of light absorption in organic and hybrid solar cells. This section will address the results of recent attempts to design nanostructures that give rise to increased performance due to novel methods of light management.

Although organic semiconductors may be cheaper and more easily processable than their inorganic counterparts, their inferior electrical properties enforce a compromise between efficient light harvesting and efficient charge collection. The nature of this compromise is determined to a large extent by the thickness of the organic layer. Whereas bulk-heterojunction devices with sufficiently thick (typically greater than a couple of hundred $\mathrm{nm}$ ) organic layers may be able to absorb all incident photons within the semiconductor's absorption band, they generally suffer from high charge-carrier recombination. Conversely, devices with thin organic layers (typically not more than $100 \mathrm{~nm}$ thick) absorb poorly despite displaying low charge-carrier recombination. This dilemma can be resolved by "trapping" incident light in the active layer. Solar cells with thin organic layers that are fitted with effective light trapping systems can therefore achieve absorption equivalent to that of a much thicker layer, and nevertheless retain their good charge transport properties.

Therefore, the best candidate for light trapping is a device with a thin active layer which has good charge collection properties. Some material combinations have already been shown to have exactly these features. Devices featuring $80 \mathrm{~nm}$ active films of poly(-heptadecanyl-2,7-carbazole-alt-5,5-(-di-2-thienylbenzothiadiazole) (PCDTBT) $/ \mathrm{PC}_{70} \mathrm{BM}$ have recently reported to have an internal quantum efficiency (IQE) that approaches $100 \%$ (at $450 \mathrm{~nm}$ ), a direct indication of efficient charge carrier generation and collection. ${ }^{[154]} \mathrm{A}$ robust light trapping scheme can then be implemented in such a device, resulting in a device with high internal and external quantum efficiencies.

It is also appealing (for thin-film photovoltaics in general) to construct solar cells with thinner active layers from the perspective of raw material availability. Photovoltaic technologies based on scarce materials such as indium will be able to considerably reduce their manufacturing costs through light trapping.

When discussing light trapping, it is vital to consider the exact nature of the correlation between absorption enhancement in the active layer and enhancement in the power conversion efficiency. This correlation is not trivial, and is highly dependent on the semiconductor. Assuming the light trapping system leaves the IQE unchanged, the increase in absorption will only lead to a proportional increase in photocurrent if it is not saturated by recombination.

The performance of solar cells under illumination levels greater than one sun provides a good insight. For the case of inorganic solar cells, a strong positive correlation between absorption and power conversion efficiency is clear, as concentrated sunlight of up to multiple hundreds of suns is routinely used to achieve high power conversion efficiencies. However, for organic solar cells, it is not so straight forward. Recent studies of P3HT:PCBM inverted cells have shown that the power conversion efficiency decreases significantly for illuminations of 10 suns or more. ${ }^{[155]}$ Recombination seems to indeed be the source of the decrease in performance, as the fill-factor undergoes a strong reduction despite the $I_{\mathrm{SC}}$ and $V_{\mathrm{OC}}$ increasing. Importantly, however, the efficiency does remain relatively constant under illumination levels of $0.5-2.5$ suns. These results are promising for the implementation of light trapping in organic solar cells, as they imply that if a light trapping scheme can be implemented that doubles the light absorption in the active layer, the efficiency will be doubled in turn.

Light trapping constructions of various forms have been considered, and the interested reader is directed to the 
literature to read recent results on distributed Bragg reflectors ${ }^{[156]}$ and on macroscopic structures such as lenses, microcavities and Winston cones ${ }^{[157-159]}$ We will here, however, limit our focus to two nanostructure-based light trapping approaches that are receiving current attention in hybrid and organic photovoltaics: scattering sub-wavelength particles and plasmonics.

\subsection{Scattering Sub-Wavelength Particles}

Promoting wide-angle scattering into the absorbing layers in solar cells is a robust way of increasing the optical path length and hence absorption of the light. The geometry of the scattering object plays a critical role in determining the intensity and angular distribution of the scattered radiation. For the regime $d<\lambda$, where $d$ is the diameter of the scattering object and $\lambda$ the wavelength of incident light, the following expressions ${ }^{[160]}$ for the scattering and absorption crosssections, $C_{s c a}$ and $C_{a b}$, hold:

$C_{s c a}=\frac{2 \pi^{5}}{3}\left(\frac{d^{6}}{\lambda^{4}}\right)\left|\frac{\varepsilon-\varepsilon_{m}}{\varepsilon+2 \varepsilon_{m}}\right|^{2}$

$C_{a b}=\pi^{2}\left(\frac{d^{3}}{\lambda}\right) \operatorname{Im}\left[\frac{\varepsilon-\varepsilon_{m}}{\varepsilon+2 \varepsilon_{m}}\right]$

where $\varepsilon$ and $\varepsilon_{m}$ are the permittivities of the particle and the medium, respectively. The $\mathrm{d}^{6}$ dependence of the scattering cross section highlights the importance of the particle size on the scattering. As in the case for scattering bodies embedded in solar cells, where absorption may be an unwanted effect, it is often desirable to have scattering dominant interactions, i.e. it is desirable to ensure the ratio $Q=C_{s c a} / C_{a b}$ is maximized. For particles of diameter $d \approx \lambda$ or $d>\lambda$, the Mie solution to Maxwell's equations is required to provide an adequate description of the scattering. ${ }^{[161]}$

In silicon solar cells, front electrodes featuring textured interfaces with a roughness of the order of several hundred $\mathrm{nm}$ have been successfully implemented to achieve light trapping. ${ }^{[162]}$ The roughness of the interfaces, which could be controlled through an etching process, determines the feature size and spacing, and hence the scattering properties. In DSSCs, favorable light scattering can be achieved by exerting control over the $\mathrm{TiO}_{2}$ nanoparticles in the active layer. In DSSCs, conventional $\mathrm{TiO}_{2}$ electrodes have a nanocrystalline porous morphology obtained by sintering colloids of nanoparticles with sizes less than $30 \mathrm{~nm} .{ }^{[163]}$ The optical scattering of particles of this size is negligible as the scattering cross-section is small compared to the geometric cross-section (easily shown using Equation 1). That is also evident from the characteristic transparency of DSSCs, which demonstrates coherent propagation of light through the device. This would not be possible in the presence of significant scattering, which is a non-coherent process. The scattering of optical light can be increased upon the introduction of large diameter ( 50 and $100 \mathrm{~nm}) \mathrm{TiO}_{2}$ nanoparticles into the electrode, as shown by Wang et al. ${ }^{[164]}$ They were able to increase the power efficiency of a reference cell from 7.6 to $9.77 \%$ by constructing $\mathrm{TiO}_{2}$ electrodes that consisted of various nanoparticle sizes deposited in multiple layers. The larger particles, which scatter most strongly, were placed deeper into the electrode, to ensure that back-scattered radiation would not be lost through the front surface, but would be able to be absorbed by the intervening layers.

This concept has also been extended to scattering bodies of other shapes. Increased power conversion efficiencies have been reported for DSSCs that have highly-scattering anatase nanorods or nanotubes incorporated into the standard nanocrystalline electrodes. ${ }^{[165]}$ Regardless of the shape of the scatterer, the potential improvement obtainable by this approach is determined by a trade-off between the surface area of the porous electrode and the corresponding scattering capability. While larger particles provide more efficient scattering, they also have a reduced surface area, which limits the amount of dye that can be adsorbed and therefore the light absorption.

\subsection{Plasmonics}

This section addresses the results of recent attempts to harness the potential of surface plasmons (SPs) to achieve light trapping. SPs are typically classified into two types of excitations. The first is the surface plasmon polariton (SPP), an electromagnetic wave that is coupled to the electron plasma of a metal and propagates at the interface of the metal with a dielectric. The second is the localized surface plasmon (LSP), an excitation of conduction electrons coupled to an external electromagnetic field. The typical metals of choice for the excitation of SPs are $\mathrm{Au}, \mathrm{Ag}, \mathrm{Al}$ and $\mathrm{Cu}$. Both SPPs and LSPs can give rise to near-field enhancement of electromag. netic radiation, and LSPs in particular can give rise to strong resonant light scattering. It is for these reasons that plasmonic solar cells are gaining a great deal of attention from research groups seeking to demonstrate light trapping in solar cells. ${ }^{[166,167]}$ Previous reports of plasmonic light trapping in organic solar cells have in general been based on one of three excitation geometries: external scattering metal nanoparticles, embedded metal nanoparticles and nanostructured electrodes. The following sections will address each of these geometries in turn.

\subsubsection{External Scattering Metal Nanoparticles}

Favorable plasmonic in-coupling of scattered light from an external layer of metallic nanoparticles into the absorbing medium in solar cells has been reported across multiple solar cell types. In a typical configuration, $\mathrm{Ag}$ or $\mathrm{Au}$ nanoparticles are deposited onto the front surface of the solar cell, either embedded into the front electrode or electronically isolated by an intermediate transparent dielectric layer. By selecting nanoparticle sizes that are favorable for scattering (of the order of $100 \mathrm{~nm}$ ) and appropriate nanoparticle area coverage, scattering can increase the light's path length in the absorbing medium. As a result, the light absorption can be improved, along with it the power conversion efficiency. This configuration has been 
Table 2. Reported enhancements in power conversion efficiency in organic cells incorporating metallic nanostructures.

\begin{tabular}{|c|c|c|c|c|}
\hline Metal & Deposition Technique & Reference Efficiency (\%) & Enhanced Efficiency (\%) & Reference \\
\hline $\mathrm{Ag}$ & Pulse-current electrodeposition & 3.05 & 3.69 & [171] \\
\hline $\mathrm{Au}$ & Electrostatic assembley & 3.04 & 3.65 & [172] \\
\hline $\mathrm{Ag}$ & Vapour Phase deposition & 1.3 & 2.2 & {$[170]$} \\
\hline
\end{tabular}

used to demonstrate photocurrent enhancements in thin-film silicon solar cells ${ }^{[167]}$ and efficiency enhancements in gallium arsenide $^{[168]}$ and amorphous silicon ${ }^{[169]}$ solar cells.

This light trapping mechanism has been implemented into organic solar cells with similar success. Enhancements in the power conversion efficiency compared to control devices have been reported by a number of groups..$^{[170-172]}$ As these publications represent some of the most effective reported plasmonic light trapping systems for organic solar cells, they have been summarized in Table 2. Although the synthesis and deposition of the metal nanoparticles vary, all of the authors reported cells with Ag or Au nanoparticles embedded in a layer of PEDOT:PSS deposited on the ITO electrode.

However, an improvement in state-of-the-art efficiency for organic solar cells through the use of plasmonics is still yet to be demonstrated. Moreover, it is often difficult to confidently attribute photocurrent enhancements to plasmonic effects alone, and more consideration of the role of other effects such as the improved series resistance (due the incorporation of $\mathrm{Ag}$ in ITO electrodes) is required. ${ }^{[173]}$

One important consideration is the role played by the order of the scattering bodies. Methods of depositing scattering particles with highly-ordered geometries ${ }^{[168,173]}$ are promising avenues to improve upon the performance of previously reported organic plasmonic devices (see Table 2), which feature completely disordered arrays of scattering particles. Not only do highly ordered arrays offer the benefit of hosting additional, order-sensitive electromagnetic modes, ${ }^{[174]}$ but they are also more suitable candidates for simulation.

The approach of depositing nanoparticles onto the front electrode can also be extended to realize structures that promote the propagation of nanocavity modes within the organic layer. ${ }^{[175]}$ In this configuration, the front electrode is patterned by an array of $250 \mathrm{~nm}$ wide $\mathrm{Ag}$ stripes. The light scattered from the stripes then becomes confined in the space between the stripes and the opposing electrode. An increase in conversion efficiency was reported for test micrometer scale devices incorporating these electrodes.

In addition to coupling incident light to modes traveling perpendicular to the device plane, it is also possible to excite waveguide modes which propagate in the active layer parallel to the device plane. Arrays of Ag stripes oriented on the front electrode can also act as a suitable excitation geometry for this purpose, with efficient scattering into waveguide modes possible in addition to the near field enhancement. ${ }^{[176]}$ Simulations indicate that photocurrent enhancements of up to $43 \%$ are possible for thin-film silicon cells. In a study of a similar geometry for amorphous silicon cells, large enhancements in absorption were also predicted, citing large enhancements due to near-field plasmonic enhancement for TM excitation, and coupling to waveguide modes for both TE and TM excitation. ${ }^{[177]}$ Although the excitation of waveguide modes in 3D nanowire DSSCs has been considered, ${ }^{[178]}$ there have been no reports on waveguide excitation using metal nanostructures in either hybrid or organic solar cells to the best of our knowledge.

\subsubsection{Embedded Nanoparticles}

An alternative construction features metallic nanoparticles embedded in the active layer itself, rather than situated on the electrode. In this configuration a number of additional processes must be considered. In comparison to the external scattering layer devices, back-scattering as well as forward scattering may lead to enhanced absorption in the active layer. A second important process is the LSP near-field enhancement of the electromagnetic field which gives rise to an absorption enhancement in the active material immediately surrounding the nanoparticles. A third important process is the charge recombination at the metal-organic interface, which must be minimized in order for the incorporation of the nanoparticles to have a net positive effect on the power conversion efficiency. To prevent embedded metallic particles acting as recombination centers within the active layer, coatings of insulating materials have been recommended. ${ }^{[179]}$

Plasmonic enhancement has been reported for organic tandem cells featuring an embedded array of silver nanoparticles. ${ }^{[179]}$ The enhancement was attributed to near-field optical enhancement that was claimed to extend up to $10 \mathrm{~nm}$ from the surface of the particles. Simulations of metallic nanoparticles embedded in organic films can estimate the maximum possible enhancement that can be provided by this light trapping configuration. One study reported absorption enhancements of the order of 1.5 for devices made from P3HT:PCBM featuring an array of $23 \mathrm{~nm}$ diameter nanoparticles with a spacing of $40 \mathrm{~nm}$ in a film. ${ }^{[180]}$

The shape of the metallic nanoparticle has a large influence on its interaction with light. A recent study used nanoprisms as metallic additives to the active layer, in place of the conventional spherical nanoparticles. ${ }^{[181]}$ Nanoprisms have the advantage that their plasmon resonances are highly tunable within the visible and near IR wavelengths. ${ }^{[182]}$ This could lead to the opportunity to tune the plasmonic resonance and optimize absorption enhancement for any given active material.

\subsubsection{Structured Electrodes}

In a third geometry, plasmonic modes are directly excited on metallic (back) electrodes in solar cells. In order to achieve excitation from normally incident solar radiation, the electrode can be structured with either ordered features such as nanowires 


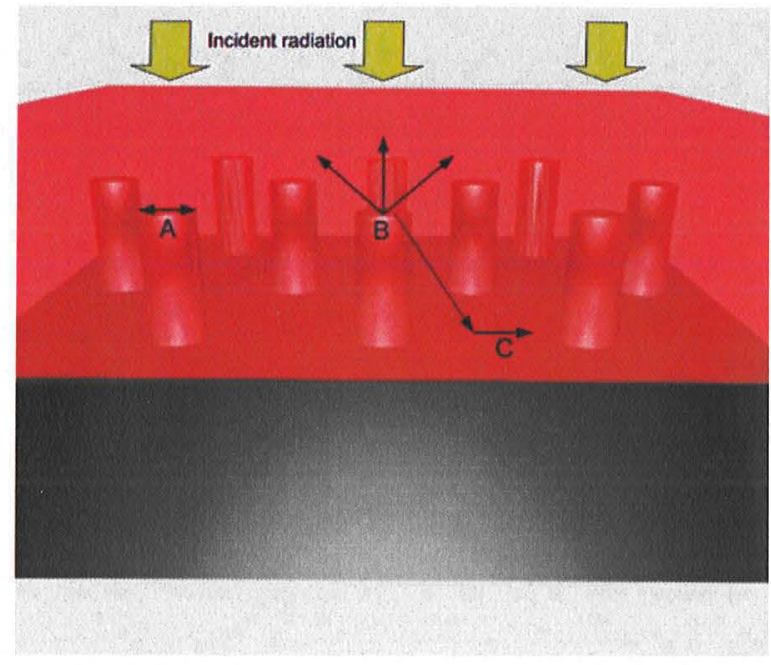

Figure 9. A semiconductor film deposited on a structured electrode, which consists of an array of free-standing metallic nanowires on a dense metal film. Light trapping can be achieved in the semiconductor film as a result of mechanisms such as A: excitation of localised surface plasmons (LSPs) on the metal nanostructure, B: light scattering from sub-wavelength features and $C$ : excitation (from scattered radiation) of surface plasmon polaritons (SPPs)

(Figure 9) or random irregularites. Light scattered from these features can then be coupled to propagating SPPs at the interface between the semiconductor and the metallic electrode. The electromagnetic energy transferred to these SPPs is essentially "trapped", traveling parallel to the plane of the device, promoting enhanced absorption in the semiconductor layer. Calculations for a poly[9,9-didecanefluorene-alt-(bis-thienylene) benzothiadiazole] (PF10TBT):PCBM-Ag interface give the promising result that the bulk of the energy density of the SPP is absorbed in the semiconductor layer, corresponding to a low energy loss due to ohmic damping of the mode in the Ag layer ${ }^{[166]} \mathrm{Ohmic}$ damping of plasmonic modes in silver electrodes can also be reduced by using appropriately chosen dielectric layers between the semiconductor and the electrode. ${ }^{[183]}$

In addition, LSPS can be excited in transverse and longitudinal directions along metal nanowires. ${ }^{[184]}$ Similar to the case of the LSPs excited on metallic nanoparticles embedded in the active layer from Section 4.2.2, the plasmonic near field enhancement due to the LSP and SPP modes on structured electrodes have the potential to lead to significant enhancements in absorption in the active layer.

Structured metallic electrodes have been considered in inorganic solar cells $\mathrm{s}^{[162,185,186]}$ and they are also receiving increased attention from organic photovoltaic researchers. Sinusoidal Ca/ $\mathrm{Al}$ electrodes have been shown to increase the conversion efficiency for P3HT:PCBM cells, ${ }^{[187]}$ the improvement attributed to diffraction grating properties of the electrode. Higher order diffracted modes with larger angles of diffraction have increased path lengths in the active layer, with the possibility for total internal reflection at the active layer-front electrode interface. In another study, a device was constructed using a periodic Al grating with a height of $50 \mathrm{~nm}$ and a period of $277 \mathrm{~nm}$ as the back electrode. ${ }^{[188]}$ The enhancement in photocurrent was attributed to near-field plasmonic enhancement of the electromagnetic field at the metal-organic interface.

Simulations have given some insight to the light coupling that can occur at structured electrodes. For a given geometry, the amount of light coupled to SPPs, waveguide modes and Fabry-Pérot resonances can be calculated using the finite difference time domain method. ${ }^{[186]}$

Devices that are constructed by depositing active layers on top of a pre-structured electrode or substrate have the benefit that all of the subsequent layers adopt the structure of the underlying layer. Improved performance has been reported for such cells. The authors cite favorable scattering into guided modes within the cell as a large contributing factor towards the enhancement. ${ }^{[189,190]}$

\section{Conclusion}

In recent years research on nanostructured solar cells has increased considerably. One major reason for this increased interest is the possibility to fabricated designed structures in nanometer dimensions. We are convinced that the research on controlled nanostructured solar cells will enable to gain better understanding of the precise physics of organic and hybrid solar cells. Controlled nanostructures with defined interfaces between donor-acceptor materials allow more accurate modeling. Even though none of the described solar cells can yet compete with the best bulk heterojunction solar cells, we are confident that improved nanofabrication techniques and improved understanding of the device physics will lead to the design of the ideal device architecture and subsequently to an improved efficiency in optimized devices.

\section{Acknowledgements}

We acknowledge support by the German Excellence Initiative of the Deutsche Forschungsgemeinschaft (DFG) via the Nanosystems Initiative Munich (NIM), the German research foundation (DFG) in the program "SPP1355: elementary processes of organic photovoltaics" and the international doctorate program NanoBioTechnology (IDK-NBT). We thank Jochen Feldmann and Jörg P. Kotthaus for access to. their laboratories and instruments.

[1] C. Wadia, A. P. Alivisatos, D. M. Kammen, Environ. Sci. Technol. 2009, 43, 2072.

[2] Y. Y. Liang, Z. Xu, J. B. Xia, S. T. Tsai, Y. Wu, G. Li, C. Ray, L. P. Yu, Adv. Mater. 2010, 22, E135.

[3] http://en.wikipedia.org/wiki/File:PVeff(rev100414).png.

[4] B. Oregan, M. Gratzel, Nature 1991, 353, 737.

[5] M. Gratzel, Acc. Chem. Res. 2009, 42, 1788.

[6] D. Venkataraman, S. Yurt, B. H. Venkatraman, N. Gavvalapalli, J. Phys. Chem. Lett. 2010, 1, 947.

[7] X. Yang, J. Loos, Macromolecules 2007, 40, 1353.

[8] A. Martinson, T. Hamann, M. Pellin, J. Hupp, Chem. Eur. J. 2008, 14,4458 . 
[9] A. Mayer, S. Scully, B. Hardin, M. Rowell, M. McGehee, Mater. Today 2007, 10, 28.

[10] B. O'Regan, J. Durrant, J. Phys. Chem. B 2006, 110, 8544.

[11] H. J. Snaith, L. Schmidt-Mende, Adv. Mater. 2007, 19, 3187.

[12] C. Stefano, C. Vito, B. Rita, A. Roberto, B. Carlo Alberto, D. Aldo, Int. J. Photoenergy 2010, 2010.

[13] D. Wei, Int. J. Mol. Sci. 2010, 11, 1103.

[14] Q. Zhang, C. Dandeneau, X. Zhou, G. Cao, Adv. Mater. 2009, 21, 4087.

[15] M. Mandoc, L. Koster, P. Blom, Appl. Phys. Lett. 2007, 90, 133504.

[16] P. E. Shaw, A. Ruseckas, I. D. W. Samuel, Adv. Mater. 2008, 20, 3516

[17] A. A. Bakulin, J. C. Hummelen, M. S. Pshenichnikov, P. H. M. van Loosdrecht, Adv. Funct. Mater. 2010, 20, 1653.

[18] R. A. Street, M. Schoendorf, Phys. Rev. B 2010, 81.

[19] R. R. Lunt, N. C. Giebink, A. A. Belak, J. B. Benziger, S. R. Forrest, J. Appl. Phys. 2009, 105.

[20] Y. Kim, S. Cook, S. M. Tuladhar, S. A. Choulis, J. Nelson, J. R. Durrant, D. D. C. Bradley, M. Giles, I. Mcculloch, C. S. Ha, M. Ree, Nat. Mater. 2006, 5, 197.

[21] S. S. Sun, Sol. Energy Mat. Sol. C 2003, 79, 257.

[22] S. K. Park, T. N. Jackson, J. E. Anthony, D. A. Mourey, Appl. Phys. Lett. 2007, 91, 063514.

[23] C. Tang, Appl. Phys. Lett. 1986, 48, 183.

[24] H. C. Hesse, J. Weickert, M. Al-Hussein, L. Dössel, X. Feng K. Müllen, L. Schmidt-Mende, Sol. Energy Mater. Sol. Cells 2010, 94, 560.

[25] W. Pisula, M. Kastler, D. Wasserfallen, J. W. F. Robertson, F. Nolde, C. Kohl, K. Mullen, Angew. Chem. Int. Ed. 2006, 45, 819.

[26] D. Venkataraman, S. Yurt, B. H. Venkatraman, N. Gavvalapalli, J.Phys. Chem. Lett. 2010, 1, 947.

[27] R. Bushby, O. Lozman, Curr. Opin. Colloid Interface Sci. 2002, 7, 343.

[28] W. Pisula, M. Zorn, J. Y. Chang, K. Mullen, R. Zentel, Macromol. Rapid Commun. 2009, 30, 1179.

[29] A. Cristadoro, M. Ai, H. Rader, J. Rabe, K. Mullen, J. Phys. Chem. C 2008, 112, 5563.

[30] H. Kim, S. Choi, J. Lee, P. Busch, S. Koza, E. Verploegen, B. Pate, Adv. Mater. 2008, 20, 1105.

[31] C. J. Brinker, Y. Lu, A. Sellinger, H. Fan, Adv. Mater. 1999, 11, 579.

[32] A. M. van de Craats, J. M. Warman, A. Fechtenkotter, J. D. Brand, M. A. Harbison, K. Mullen, Adv. Mater. 1999, 11, 1469.

[33] L. Schmidt-Mende, A. Fechtenkotter, K. Mullen, E. Moons, R. H. Friend, J. D. MacKenzie, Science 2001, 293, 1119.

[34] E. Pouzet, V. De Cupere, C. Heintz, J. W. Andreasen, D. W. Breiby, M. M. Nielsen, P. Viville, R. Lazzaroni, G. Gbabode, Y. H. Geerts, J. Phys. Chem. C 2009, 113, 14398.

[35] W. Pisula, Z. Tomovic, B. El Hamaoui, M. D. Watson, T. Pakula, K. Mullen, Adv. Funct. Mater. 2005, 15, 893.

[36] O. Thiebaut, H. Bock, E. Grelet, J. Am. Chem. Soc. 2010, 132, 6886

[37] K. Walzer, B. Maennig, M. Pfeiffer, K. Leo, Chem. Rev. 2007, 107, 1233.

[38] S.-S. Sun, Sol. Energy Mater. Sol. Cells 2003, 79, 257.

[39] M. Sommer, S. Lindner, M. Thelakkat, Adv. Funct. Mater. 2007, 17, 1493.

[40] S. Y. Chou, P. R. Krauss, P. J. Renstrom, Appl. Phys. Lett. 1995, 67, 3114.

[41] S. Y. Chou, P. R. Krauss, P. J. Renstrom, Science 1996, 272, 85.

[42] N. Hirata, J. J. Lagref, E. J. Palomares, J. R. Durrant, M. K. Nazeeruddin, M. Gratzel, D. Di Censo, Chem. Eur. J. 2004, 10, 595.

[43] M. Aryal, F. Buyukserin, K. Mielczarek, X.-M. Zhao, J. Gao, A. Zakhidov, W. Hu, J. Vac. Sci. Technol. B 2008, 26, 2562.

[44] L. C. Chen, D. Godovsky, O. Inganäs, J. C. Hummelen, R. A. J. Janssens, M. Svensson, M. R. Andersson, Adv. Mater. 2000, $12,1367$.
[45] J. S. Kim, Y. Park, D. Y. Lee, J. H. Lee, J. H. Park, J. K. Kim, K. Cho, Adv. Funct. Mater. 2010, 20, 540

[46] M. Drees, K. Premaratne, W. Graupner, J. R. Heflin, R. M. Davis, D. Marciu, M. Miller, Appl. Phys. Lett. 2002, 81, 4607

[47] M.-S. Kim, B.-G. Kim, J. Kim, ACS Appl. Mater. Interfaces 2009, 1, 1264

[48] J. Jo, S.-S. Kim, S.-I. Na, B.-K. Yu, D.-Y. Kim, Adv. Funct. Mater. $2009,19,866$

[49] W. Wiedemann, L. Sims, A. Abdellah, A. Exner, R. Meier, K. P. Musselman, J. L. MacManus-Driscoll, P. Muller-Buschbaum, G. Scarpa, P. Lugli, L. Schmidt-Mende, Appl. Phys. Lett. 2010, 96.

[50] W. Zeng, K. S. L. Chong, H. Y. Low, E. L. Williams, T. L. Tam A. Sellinger, Thin Solid Films 2009, 517, 6833

[51] L. M. Chen, Z. R. Hong, G. Li, Y. Yang, Adv. Mater. 2009, 21, 1434.

[52] S. K. Hau, H. L. Yip, N. S. Baek, J. Y. Zou, K. O'Malley, A. K. Y. Jen, Appl. Phys. Lett. 2008, 92.

[53] Y. Sahin, S. Alem, R. de Bettignies, J. M. Nunzi, Thin Solid Films $2005,476,340$.

[54] J. Weickert, H. Sun, C. Palumbiny, H. Hesse, L. Schmidt-Mende, Sol. Energy Mater. Sol. C 2010, 94, 2371.

[55] F. C. Krebs, Sol. Energy Mater. Sol. C 2008, 92, 715.

[56] A. K. K. Kyaw, X. W. Sun, C. Y. Jiang, G. Q. Lo, D. W. Zhao, D. L. Kwong, Appl. Phys. Lett. 2008, 93.

[57] D. W. Zhao, P. Liu, X. W. Sun, S. T. Tan, L. Ke, A. K. K. Kyaw, Appl. Phys. Lett. 2009, 95.

[58] S. Guenes, N. S. Sariciftci, Inorg. Chim. Acta 2008, 361, 581.

[59] U. Bach, D. Lupo, P. Comte, J. E. Moser, F. Weissortel, J. Salbeck, H. Spreitzer, M. Gratzel, Nature 1998, 395, 583.

[60] C. K. Mor, K. Shankar, M. Paulose, O. K. Varghese, C. A. Grimes, Nano Lett. 2006, 6, 215.

[61] W. J. E. Beek, M. M. Wienk, R. A. J. Janssen, Adv. Mater. 2004, 16, 1009

[62] M. Q. Wang, X. G. Wang, Sol. Energy Mater. Sol. C 2007, 91, 1782.

[63] G. Mor, S. Kim, M. Paulose, O. Varghese, K. Shankar, J. Basham, C. Grimes, Nano Lett. 2009, 9, 4250.

[64] Y. Liang, L. Yu, Acc. Chem. Res. 2010, 43, 1227

[65] M. Jorgensen, K. Norrman, F. C. Krebs, Sol. Energy Mater. Sol. C $2008,92,686$

[66] F. C. Krebs, K. Norrman, Prog. Photovoltaics 2007, 15, 697.

[67] K. Norrman, J. Alstrup, M. Jorgensen, M. Lira-Cantu, N. B. Larsen, F. C. Krebs, Org. Photovoltaics VII 2006, 6334, U100.

[68] A. Gopferich, Biomaterials 1996, 17, 103.

[69] M. K. Wang, S. J. Moon, M. F. Xu, K. Chittibabu, P. Wang N. L. Cevey-Ha, R. Humphry-Baker, S. M. Zakeeruddin, M. Gratzel, Small 2010, 6, 319

[70] M. K. Wang, S. J. Moon, D. F. Zhou, F. Le Formal, N. L. Cevey-Ha R. Humphry-Baker, C. Gratzel, P. Wang, S. M. Zakeeruddin, M. Gratzel, Adv. Funct. Mater. 2010, 20, 1821.

[71] M. Skompska, Synt. Met. 2010, 160, 1

[72] K. M. Coakley, M. D. McGehee, Appl. Phys. Lett. 2003, 83, 3380

[73] J. Kruger, R. Plass, L. Cevey, M. Piccirelli, M. Gratzel, U. Bach, Appl. Phys. Lett. 2001, 79, 2085

[74] R. Zhu, C. Y. Jiang, B. Liu, S. Ramakrishna, Adv. Mater. 2009, 21, 994

[75] J. Boucle, P. Ravirajan, J. Nelson, J. Mater. Chem. 2007, 17, 3141.

[76] W. U. Huynh, J. J. Dittmer, A. P. Alivisatos, Science 2002, 295, 2425.

[77] W. J. E. Beek, M. M. Wienk, R. A. J. Janssen, Adv. Funct. Mater. $2006,16,1112$

[78] J. Boucle, S. Chyla, M. S. P. Shaffer, J. R. Durrant, D. D. C. Bradley, J. Nelson, Adv. Funct. Mater. 2008, 18, 622.

[79] A. I. Hochbaum, P. D. Yang, Chem. Rev. 2010, 110, 527.

[80] Y. X. Li, M. Guo, M. Zhang, X. D. Wang, Mater. Res. Bull. 2009, 44, 1232.

[81] A. Kumar, A. R. Madaria, C. W. Zhou, J. Phys. Chern. C 2010, 114, 7787. 
[82] X. J. Feng, K. Shankar, O. K. Varghese, M. Paulose, T. J. Latempa C. A. Grimes, Nano Lett. 2008, 8, 3781.

[83] X. J. Feng, K. Shankar, M. Paulose, C. A. Grimes, Angew. Chem. Int Ed. $2009,48,8095$

[84] C. Y. Kuo, W. C. Tang, C. Gau, T. F. Guo, D. Z. Jeng, Appl. Phys. Lett. 2008, 93, 033307.

[85] S. S. Williams, M. J. Hampton, V. Gowrishankar, I. K. Ding, J. L. Templeton, E. T. Samulski, J. M. DeSimone, M. D. McGehee, Chem. Mater. 2008, 20, 5229.

[86] K. P. Musselman, G. J. Mulholland, A. P. Robinson, L. Schmidt Mende, J. L. MacManus-Driscoll, Adv. Mater. 2008, 20, 4470.

[87] I. Gonzalez-Valls, M. Lira-Cantu, Energ. Environ. Sci. 2009, 2, 19.

[88] L. E. Greene, M. Law, D. H. Tan, M. Montano, J. Goldberger C. Somorjai, P. D. Yang, Nano Lett. 2005, 5, 1231.

[89] K. Musselman, A. Wisnet, D. C. Iza, H. C. Hesse, C. Scheu J. L. MacManus-Driscoll, L. Schmidt-Mende, Adv. Mater. 2010.

[90] M. Law, L. E. Greene, J. C. Johnson, R. Saykally, P. D. Yang, Nat. Mater. 2005, 4, 455

[91] D. C. Olson, J. Piris, R. T. Collins, S. E. Shaheen, D. S. Ginley, Thin Solid Films 2006, 496, 26.

[92] D. C. Olson, S. E. Shaheen, M. S. White, W. J. Mitchell, M. F. A. M. van Hest, R. T. Collins, D. S. Ginley, Adv. Funct. Mater. 2007, 17 264.

[93] P. Ravirajan, A. M. Peiro, M. K. Nazeeruddin, M. Graetzel, D. D. C. Bradley, J. R. Durrant, J. Nelson, J. Phys. Chem. B 2006, 110, 7635.

[94] K. Takanezawa, K. Hirota, Q. S. Wei, K. Tajima, K. Hashimoto, J. Phys. Chem. C 2007, 111, 7218.

[95] M. S. White, D. C. Olson, S. E. Shaheen, N. Kopidakis, D. S. Ginley Appl. Phys. Lett. 2006, 89

[96] A. L. Briseno, T. W. Holcombe, A. I. Boukai, E. C. Garnett S. W. Shelton, J. J. M. Frechet, P. D. Yang, Nano Lett. 2010, 10, 334.

[97] B. Schwenzer, J. R. Neilson, K. Sivula, C. Woo, J. M. J. Frehet, D. E. Morse, Thin Solid Films 2009, 517, 5722

[98] G. K. Mor, O. K. Varghese, M. Paulose, K. Shankar, C. A. Grimes, Sol. Energy Mater. Sol. C 2006, 90, 2011.

[99] A. Chicov, P. Schmuki, Chem. Commun. 2009, 2791.

[100] D. Gong, C. A. Grimes, O. K. Varghese, W. C. Hu, R. S. Singh, Z. Chen, E. C. Dickey, J. Mater. Res. 2001, 16, 3331.

[101] K. Shankar, G. K. Mor, H. E. Prakasam, S. Yoriya, M. Paulose O. K. Varghese, C. A. Grimes, Nanotechnology 2007, 18, 3953.

[102] H. E. Prakasam, K. Shankar, M. Paulose, O. K. Varghese, C. A. Grimes, J. Phys. Chem. C 2007, 111, 7235

[103] G. K. Mor, O. K. Varghese, M. Paulose, C. A. Grimes, Adv. Funct Mater. 2005, 15, 1291

[104] M. Paulose, K. Shankar, O. K. Varghese, G. K. Mor, B. Hardin, C. A. Grimes, Nanotechnology 2006, 17, 1446.

[105] J. Weickert, C. Palumbiny, M. Nedelcu, T. Bein, L. Schmidt-Mende, Chem. Mater. 2011, DOI:10.1021/cm102389m.

[106] K. Shankar, J. Bandara, M. Paulose, H. Wietasch, O. K. Varghese G. K. Mor, T. J. LaTempa, M. Thelakkat, C. A. Grimes, Nano Lett. 2008, 8, 1654 .

[107] R. Beranek, H. Tsuchiya, T. Sugishima, J. M. Macak, L. Taveira, S. Fujimoto, H. Kisch, P. Schmuki, Appl. Phys. Lett. 2005, 87.

[108] G. K. Mor, K. Shankar, M. Paulose, O. K. Varghese, C. A. Grimes, Appl. Phys. Lett. 2007, 91, 152111.

[109] T. R. B. Foong, Y. D. Shen, X. Hu, A. Sellinger, Adv. Funct. Mater. 2010, 20, 1390.

[110] O. Jessensky, F. Muller, U. Gosele, Appl. Phys. Lett. 1998, 72, 1173

[111] S. I. Na, S. S. Kim, W. K. Hong, J. W. Park, J. Jo, Y. C. Nah, T. Lee, D. Y. Kim, Electrochim. Acta 2008, 53, 2560

[112] H. D. Yu, Z. P. Zhang, M. Y. Han, X. T. Hao, F. R. Zhu, J. Am. Chem. Soc. 2005, 127, 2378.

[113] Y. Sun, G. M. Fuge, N. A. Fox, D. J. Riley, M. N. R. Ashfold Adv. Mater. 2005, 17, 2477
[114] A. B. F. Martinson, J. W. Elam, J. T. Hupp, M. J. Pellin, Nano Lett $2007,7,2183$

[115] P. M. Sommeling, B. C. O'Regan, R. R. Haswell, H. J. P. Smit, N. J. Bakker, J. J. T. Smits, J. M. Kroon, J. A. M. van Roosmalen, J. Phys. Chem. B 2006, 110, 19191.

[116] L. Schmidt-Mende, J. E. Kroeze, J. R. Durrant, M. K. Nazeeruddin, M. Gratzel, Nano Lett. 2005, 5, 1315.

[117] Y. X. Liu, S. R. Scully, M. D. McGehee, J. S. Liu, C. K. Luscombe, J. M. J. Frechet, S. E. Shaheen, D. S. Ginley, J. Phys. Chem. B 2006, 110, 3257

[118] M. T. Lloyd, R. P. Prasankumar, M. B. Sinclair, A. C. Mayer, D. C. Olson, J. W. P. Hsu, J. Mater. Chem. 2009, 19, 4609.

[119] C. J. Bhongale, M. Thelakkat, Sol. Energy Mater. Sol. C 2010, 94, 817.

[120] Y. Vaynzof, D. Kabra, L. H. Zhao, P. K. H. Ho, A. T. S. Wee, R. H. Friend, Appl. Phys. Lett. 2010, 97.

[121] M. M. Wienk, J. M. Kroon, W. J. H. Verhees, J. Knol, J. C. Hummelen, P. A. van Hal, R. A. J. Janssen, Angew. Chem. Int. Ed. 2003, 42, 3371.

[122] T. L. Ma, M. Akiyama, E. Abe, I. Imai, Nano Lett. 2005, 5, 2543.

[123] R. P. Vitiello, J. M. Macak, A. Ghicov, H. Tsuchiya, L. F. P. Dick, P. Schmuki, Electrochem Commun 2006, 8, 544.

[124] M. Law, L. E. Greene, A. Radenovic, T. Kuykendall, J. Liphardt, P. D. Yang, J. Phys. Chem. B 2006, 110, 22652.

[125] L. E. Greene, M. Law, B. D. Yuhas, P. D. Yang, J. Phys. Chem. C $2007,111,18451$.

[126] Y. Z. Hao, J. Pei, Y. Wei, Y. H. Cao, S. H. Jiao, F. Zhu, J. J. Li, D. H. Xu, J. Phys. Chem. C 2010, 114, 8622.

[127] S. A. Haque, E. Palomares, H. M. Upadhyaya, L. Otley, R. J. Potter, A. B. Holmes, I. R. Durrant, Chem Commun 2003, 3008.

[128] J. N. Clifford, E. Palomares, M. K. Nazeeruddin, M. Gratzel, I. Nelson, X. Li, N. J. Long, J. R. Durrant, J. Am. Chem. Soc. 2004, 126,5225

[129] H. J. Snaith, A. Petrozza, S. Ito, H. Miura, M. Gratzel, Adv. Funct. Mater. 2009, 19, 1810

[130] S. A. Haque, S. Handa, K. Peter, E. Palomares, M. Thelakkat, J. R. Durrant, Angew. Chem. Int. Ed. 2005, 44, 5740.

[131] P. Bonhote, J. E. Moser, R. Humphry-Baker, N. Vlachopoulos, S. M. Zakeeruddin, L. Walder, M. Gratzel, J. Am. Chem. Soc. 1999, $121,1324$.

[132] M. Quintana, T. Edvinsson, A. Hagfeldt, G. Boschloo, J. Phys. Chem. C 2007, 111, 1035.

[133] M. Adachi, Y. Murata, J. Takao, J. T. Jiu, M. Sakamoto, F. M. Wang, J. Am. Chem. Soc. 2004, 126, 14943 .

[134] G. Schlichthorl, N. G. Park, A. J. Frank, J. Phys. Chem. B 1999, 103, 782

[135] G. Franco, J. Gehring, L. M. Peter, E. A. Ponomarev, I. Uhlendorf, J. Phys. Chem. B 1999, 103, 692.

[136] L. Dloczik, O. lleperuma, I. Lauermann, L. M. Peter E. A. Ponomarev, G. Redmond, N. J. Shaw, I. Uhlendorf, J. Phys. Chem. B 1997, 101, 10281.

[137] ]. Bisquert, J. Phys. Chem. B 2004, 108, 2323.

[138] T. Tiedje, A. Rose, Solid State Commun. 1981, 37, 49.

[139] ]. Orenstein, M. Kastner, Phys. Rev. Lett. 1981, 46, 1421.

[140] S. Guldin, S. Hüttner, P. Tiwana, M. C. Orilall, B. Ülgüt, M. Stefik, M. Kolle, G. Divitini, C. Ducati, S. Redfern, H. J. Snaith, U. Wiesner, D. Eder, U. Steiner, to be published 2010.

[141] E. Hendry, M. Koeberg, B. O'Regan, M. Bonn, Nano Lett. 2006, 6, 755.

[142] G. Li, V. Shrotriya, J. S. Huang, Y. Yao, T. Moriarty, K. Emery, Y. Yang, Nat. Mater. 2005, 4, 864.

[143] D. Poplavskyy, J. Nelson, D. D. C. Bradley, Appl. Phys. Lett. 2003 $83,707$.

[144] H. J. Snaith, M. Gratzel, Appl. Phys. Lett. 2006, 89

[145] F. Fabregat-Santiagoa, J. Bisquert, E. Palomares, S. A. Haque, I. R. Durrant, J. Appl. Phys. 2006, 100 
[146] M. Aryal, K. Trivedi, W. C. Hu, ACS Nano 2009, 3, 3085.

[147] H. Sirringhaus, P. J. Brown, R. H. Friend, M. M. Nielsen, K. Bechgaard, B. M. W. Langeveld-Voss, A. J. H. Spiering, R. A. J. Janssen, E. W. Meijer, P. Herwig, D. M. de Leeuw, Nature $1999,401,685$

[148] H. Sirringhaus, R. J. Wilson, R. H. Friend, M. Inbasekaran, W. Wu, E. P. Woo, M. Grell, D. D. C. Bradley, Appl. Phys. Lett. 2000, 77, 406.

[149] K. M. Coakley, B. S. Srinivasan, J. M. Ziebarth, C. Goh, Y. X. Liu, M. D. McGehee, Adv. Funct. Mater. 2005, 15, 1927.

[150] N. W. Duffy, L. M. Peter, R. M. G. Rajapakse, K. G. U. Wijayantha, Electrochem. Commun. 2000, 2, 658.

[151] S. Pelet, J. E. Moser, M. Gratzel, J. Phys. Chem. B 2000, 104, 1791.

[152] V. D. Mihailetchi, J. Wildeman, P. W. M. Blom, Phys. Rev. Lett. 2005, 94.

[153] J. Weickert, S. Haiyan, C. Palumbiny, H. C. Hesse, L. Schmidt-Mende, Sol. Energy Mater. Sol. C 2010.

[154] S. H. Park, A. Roy, S. Beaupre, S. Cho, N. Coates, J. S. Moon, D. Moses, M. Leclerc, K. Lee, A. J. Heeger, Nat. Photonics 2009, 3, 297.

[155] T. Tromholt, E. A. Katz, B. Hirsch, A. Vossier, F. C. Krebs, Appl. Phys. Lett. 2010, 96.

[156] S. Colodrero, A. Mihi, L. Haggman, M. Ocana, G. Boschloo, A. Hagfeldt, H. Miguez, Adv. Mater. 2009, 21, 764.

[157] M. Niggemann, M. Riede, A. Gombert, K. Leo, Phys. Status Solidi A 2008, 205, 2862.

[158] S. D. Zilio, K. Tvingstedt, O. Inganas, M. Tormen, Microelectronic Engineering 2009, 86, 1150.

[159] P. Peumans, V. Bulovic, S. R. Forrest, Appl. Phys. Lett. 2000, 76, 2650.

[160] C. F. Bohren, D. R. Huffman, Absorption and Scattering of Light By Small Particles, Wiley-Interscience, New York 1983.

[161] G. Mie, Ann. Phys. 1908, 26, 597.

[162] J. Muller, B. Rech, J. Springer, M. Vanecek, Sol. Energy 2004, 77, 917.

[163] M. K. Nazeeruddin, A. Kay, I. Rodicio, R. Humphrybaker, E. Muller, P. Liska, N. Vlachopoulos, M. Gratzel, J. Am. Chem. Soc. 1993, $115,6382$.

[164] Z. S. Wang, H. Kawauchi, T. Kashima, H. Arakawa, Coordin. Chem. Rev. 2004, 248, 1381.

[165] J. H. Yoon, S. R. Jang, R. Vittal, J. Lee, K. J. Kim, J. Photochem. Photobiol. A 2006, 180, 184

[166] H. A. Atwater, A. Polman, Nat. Mater. 2010, 9, 205.

[167] S. Pillai, K. R. Catchpole, T. Trupke, M. A. Green, J. Appl. Phys. 2007, 101.

[168] K. Nakayama, K. Tanabe, H. A. Atwater, Appl. Phys. Lett. 2008, 93

[169] D. Derkacs, S. H. Lim, P. Matheu, W. Mar, E. T. Yu, Appl. Phys. Lett. $2006,89$.
[170] A. J. Morfa, K. L. Rowlen, T. H. Reilly, M. J. Romero, J. van de Lagemaat, Appl. Phys. Lett. 2008, 92.

[171] S. S. Kim, S. I. Na, J. Jo, D. Y. Kim, Y. C. Nah, Appl. Phys. Lett. 2008, 93.

[172] J. H. Lee, J. H. Park, J. S. Kim, D. Y. Lee, K. Cho, Org. Electron. 2009, 10, 416.

[173] W. J. Yoon, K. Y. Jung, J. W. Liu, T. Duraisamy, R. Revur, F. L. Teixeira, S. Sengupta, P. R. Berger, Sol. Energy Mater. Sol. C 2010, 94, 128.

[174] S. H. Lim, D. Derkacs, E. T. Yu, J. Appl. Phys. 2009, 105.

[175] N. C. Lindquist, W. A. Luhman, S. H. Oh, R. J. Holmes, Appl. Phys. Lett. 2008, 93.

[176] R. A. Pala, J. White, E. Barnard, J. Liu, M. L. Brongersma, Adv. Mater. 2009, 21, 3504

[177] N. C. Panoiu, R. M. Osgood, Opt. Lett. 2007, 32, 2825.

[178] Y. G. Wei, C. Xu, S. Xu, C. Li, W. Z. Wu, Z. L. Wang, Nano Lett. 2010, 10, 2092.

[179] B. P. Rand, P. Peumans, S. R. Forrest, J. Appl. Phys. 2004, 96, 7519.

[180] H. H. Shen, P. Bienstman, B. Maes, J. Appl. Phys. 2009, 106

[181] A. P. Kulkarni, K. M. Noone, K. Munechika, S. R. Guyer, D. S. Ginger, Nano Lett. 2010, 10, 1501.

[182] V. Bastys, I. Pastoriza-Santos, B. Rodriguez-Gonzalez, R. Vaisnoras, L. M. Liz-Marzan, Adv. Funct. Mater. 2006, 16, 766

[183] F. J. Haug, T. Soderstrom, O. Cubero, V. Terrazzoni-Daudrix, C. Ballif, J. Appl. Phys. 2008, 104.

[184] P. R. Evans, R. Kullock, W. R. Hendren, R. Atkinson, R. J. Pollard, L. M. Eng, Adv. Funct. Mater. 2008, 18, 1075.

[185] R. H. Franken, R. L. Stolk, H. Li, C. H. M. van der Werf, J. K. Rath R. E. I. Schropp, J. Appl. Phys. 2007, 102.

[186] V. E. Ferry, L. A. Sweatlock, D. Pacifici, H. A. Atwater, Nano Lett. $2008,8,4391$.

[187] S. I. Na, S. S. Kim, J. Jo, S. H. Oh, J. Kim, D. Y. Kim, Adv. Funct. Mater. 2008, 18, 3956.

[188] K. Tvingstedt, N. K. Persson, O. Inganas, A. Rahachou, I. V. Zozoulenko, Appl. Phys. Lett. 2007, 91.

[189] J. Zhu, C. M. Hsu, Z. F. Yu, S. H. Fan, Y. Cui, Nano Lett. 2010, 10, 1979.

[190] V. E. Ferry, M. A. Verschuuren, H. B. T. Li, E. Verhagen, R. J. Walters R. E. I. Schropp, H. A. Atwater, A. Polman, Opt. Express 2010, 18, A237.

[191] A. Santos, P. Formentín, J. Pallarés, J. Ferré-Borrull, L. F. Marsal, Solar Energy Mater. Solar Cells 2010, 94, 1247.

[192] X. He, F. Gao, G. Tu, D. Hasko, S. Hu'tner, U. Steiner, N. C. Greenham, R. H. Friend, W. T. S. Huck, Nano Lett. 2010, 10, 1302. 